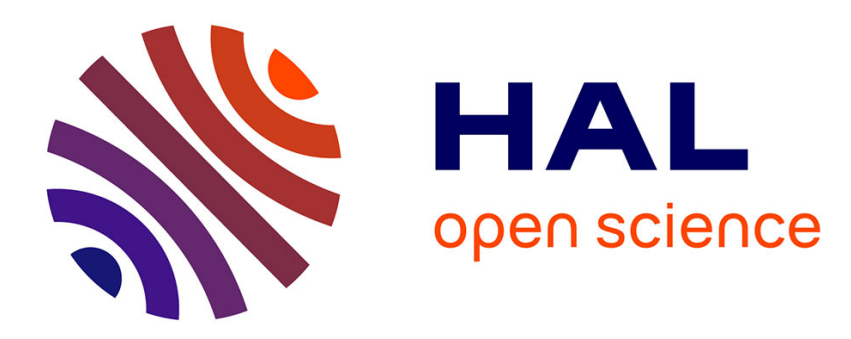

\title{
A mixed system of agreement in the suffix classes of Lealao Chinantec
}

\author{
Enrique L. Palancar
}

\section{To cite this version:}

Enrique L. Palancar. A mixed system of agreement in the suffix classes of Lealao Chinantec. Geomorphology, 2014, pp.01. 10.1007/s11525-014-9252-x . hal-01099325

\section{HAL Id: hal-01099325 \\ https://hal.science/hal-01099325}

Submitted on 2 Jan 2015

HAL is a multi-disciplinary open access archive for the deposit and dissemination of scientific research documents, whether they are published or not. The documents may come from teaching and research institutions in France or abroad, or from public or private research centers.
L'archive ouverte pluridisciplinaire HAL, est destinée au dépôt et à la diffusion de documents scientifiques de niveau recherche, publiés ou non, émanant des établissements d'enseignement et de recherche français ou étrangers, des laboratoires publics ou privés. 


\title{
A mixed system of agreement in the suffix classes of Lealao Chinantec
}

Enrique L. Palancar

Structure et Dynamique des Langues-CELIA (UMR8202), CNRS

Surrey Morphology Group, University of Surrey

Accepted in Morphology, Nov. 2014

\begin{abstract}
In Lealao Chinantec, an Oto-Manguean language of Mexico, verbs receive a set of suffixes which index person and number of the subject. There are various sets of such affixes producing the sort of allomorphy that is typical of inflectional classes. In this paper, I study the distribution of such suffixes in a large sample of verbs from Rupp and Rupp's (1996) dictionary and show that the allomorphy is largely morphosyntactically motivated for a group of verbs that have two paradigms, animate and inanimate. For many other verbs this morphosyntactic mapping fails and the allomorphy we observe is essentially morphological in nature. This allomorphy reflects the interaction of what I treat as two competing systems of agreement. One such system is a more canonical agreement system based on subject (S/A), the other is based on animacy agreement with the absolutive argument $(\mathrm{S} / \mathrm{O})$ (also found in other Chinantecan languages). These two systems and the way they talk to each other has important consequences for the morphology-syntax interface of Lealao Chinantec.
\end{abstract}

\section{Keywords}

Chinantec, Oto-Manguean, inflectional classes, animacy, agreement

Acknowledgements: This paper was written under the auspices of the ESRC/AHRC project RES-062-23-3126 "Endangered Complexity: Inflectional classes in Oto-Manguean languages". I want to thank Matthew Baerman and Greville Corbett for their invaluable comments on an earlier draft of this paper. I owe my gratitude to the two anonymous reviewers and the main editor of Morphology for all their wise comments and suggestions which helped me improve the article considerably. I presented a version of this paper at a talk at the 2013 Meeting of the SSILA at Boston. Another version was presented at the Seminar TypUlm at the École Normale Supérieure of Paris in 2014. I am grateful for all the feedback received. I am also thankful to Penelope Everson for proofreading my English. All errors and deficiencies remain my own responsibility. 


\section{Introduction}

The Chinantecan languages (Oto-Manguean) of Mexico have started to awaken interest in word-and-paradigm approaches to morphology. This can be seen in a number of recent publications, such as for example Baerman (2013b), Baerman and Palancar (forthcoming); Baerman (2014a); Brown and Evans (2013); Corbett and Baerman (2006); Finkel and Stump (2007, 2009); Palancar 2014); Stump and Finkel (2013), etc.

Such an interest is justified. It is based on a growing acknowledgement -sometimes not without a tinge of bewilderment- that the inflection of Chinantecan languages ranks amongst the most intricate in the world's languages. This is mainly due to the fact that inflected forms in these languages result from the interaction of multiple systems of classification, which are for the most part mutually independent from each other. Typical such systems in the family are the prosodic classes (made by tone and stress) and the stem alternation patterns, but the language known as Lealao Chinantec is remarkable within this family in also having different sets of person and number suffixes. These suffixes add yet another layer of complexity to the inflectional system because some verbs take a given set, as for example the verb in (1), while other verbs take a different set, as for example the verb in (2). ${ }^{1}$ For convenience, the examples illustrate only singular forms in the future tense. ${ }^{2}$

\begin{tabular}{|c|c|c|c|}
\hline (1) & $\begin{array}{l}P^{A} \text { nuй }(\mathrm{tr}) \\
\text { 'hear } \\
\text { something' }\end{array}$ & (2) & $\begin{array}{l}P^{A} x i e e^{2} y(\operatorname{tr}) \\
\text { 'deduct } \\
\text { something' }\end{array}$ \\
\hline & FUT & & FUT \\
\hline $1 \mathrm{SG}$ & $\mathrm{Pi}^{2}-n u u^{42}-\mathbf{y}$ & $1 \mathrm{SG}$ & $\operatorname{li}^{2}-$ xiaa $^{1}$-á $^{2}$ \\
\hline $2 \mathrm{SG}$ & $\mathrm{Pi}^{2}-n u u^{3}-\mathbf{y}$ & $2 \mathrm{SG}$ & $\mathrm{Pi}^{2}-\mathrm{xiaa}^{4}-\mathbf{u}^{3}$ \\
\hline $3 \mathrm{SG}$ & ?í $^{4}-$ nuú ${ }^{4}-\varnothing$ & $3 \mathrm{SG}$ & $i^{4} 1^{4}-x_{i e e^{2}}^{2} \mathbf{y}$ \\
\hline
\end{tabular}

The Lealao Chinantec verbs in (1) and (2) could be said to belong to two different inflectional classes because they select different suffix sets: the class selecting- $y /-y /-\varnothing$ and the class selecting $-a^{2} /-u^{3} /-y{ }^{3}$ Rupp \& Rupp (1996) identify four such classes, given in (3), but I argue in $\$ 3.1$ that in reality we can talk of six. The classes have a different membership size: some contain hundreds of verbs, some just a handful.

\begin{tabular}{|c|c|c|c|c|}
\hline (3) & Class I & Class II & Class III & Class IV \\
\hline $1 \mathrm{SG}$ & $-\mathrm{y}$ & $-a^{4}$ & $-a^{4}$ & $-y$ \\
\hline $\mathrm{SG}$ & $-y$ & $-u^{3}$ & $-y$ & $-u^{3}$ \\
\hline SG & $-\varnothing$ & $-y$ & $-\varnothing$ & $-\varnothing /-?$ \\
\hline
\end{tabular}

\footnotetext{
${ }^{1}$ Tone is indicated by numbers. There are four level tones (very high 1, high 2, mid 3 and low 4) and two ascending contour tones (mid-high 32 and low-high 42). Acute stress indicates 'ballistic stress' treated in $\S 2.1 \mathrm{~A}$ nasal vowel is represented as an underlined vowel.

${ }^{2}$ Abbreviations: AN: animate; Cl.: class; CPL: completive; DEICT: deicitic; EXCL: exclusive; FUT: future; INAN: inanimate; INCL: inclusive; INCPL: incompletive; INFL: inflectional; intr: intransitive; IRR: irrealis; PL: plural; PRF: perfect; PRS: present; PST: past; RELAT: relational; SG: singular; SUB: subject; tr: transitive.

${ }^{3}$ As we will see in $\S 3.1$, the suffix $-y$ is a palatal consonant that cannot bear tone.
} 
In this paper, I show that these suffix classes constitute an interesting object of study for morphological theory because they instantiate a type of inflection mixing two systems of verbal agreement, one involving person-number agreement with subject (S/A) and another animacy agreement with the $\mathrm{S} / \mathrm{O}$ argument. Different verbs make use of such systems differently.

The lexicographic tradition of the SIL treats animacy agreement as a lexical phenomenon that involves two different verbs which are given their own independent entry in the dictionaries: one being the inanimate verb, the other the animate one as in an animacy pair. An example of such a pair is given in (4-5). The treatment of these verbs as being two lexical items has been justified by them having different prosodic inflection, but in this paper I argue that the forms involved could be alternatively viewed as instantiating two different paradigms of the same verbal lexeme.

$$
\begin{aligned}
& P^{4} \operatorname{lá}^{2} \text { (tr) } \\
& \text { 'get }
\end{aligned}
$$

something

down'

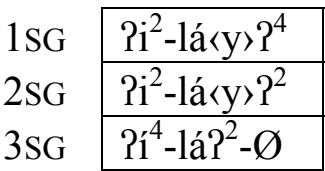

(5) Pi láy? $^{4}(\mathrm{tr})$

'get

an animate

\begin{tabular}{|c|c|}
\hline \multicolumn{2}{|c|}{ FUT } \\
\hline $1 \mathrm{SG}$ & $i^{2}-1 a P^{42}-a^{2}$ \\
\hline $2 \mathrm{SC}$ & $P i^{2}-l a ́ ?^{1}-u^{3}$ \\
\hline & Pí $^{4}-1 a ́\langle y\rangle ?^{4}$ \\
\hline
\end{tabular}

entity down'

Besides prosodic formatives, the animacy pair in (4-5) also contrasts in the affix set they select. Like (1) and (2), the verb in (4) would belong to Class I given in (3), while (5) would belong to Class II. $^{4}$ I argue in $\S 4$ that the selection of the suffix sets responds to the morphosyntactic machinery of animacy agreement, and for such verbs there is no need to understand the suffix sets as having inflectional class organization. However, I also show in $\S 5$ that such machinery ceases to be operational when one zooms out from this core into the lexicon at large, where the distribution of the suffixes with inanimate verbs such as (3) becomes less predictable and should be better accounted for as a lexical matter, which justifies in turn their organization in inflectional classes. Notice for example that the verb in (2) has an inanimate $\mathrm{O}$ just like the verbs in (1) or (4), but receives the same suffixes as the animate verb in (5). In this respect, I claim that the set in (2) and to a large extent in (4) responds to the other agreement system at play and signals person-number agreement of subject, instead of animacy.

The paper has the following structure. In the next section, I introduce basic notions about both verbal inflection and animacy gender in Lealao Chinantec. This leads in $\S 3$ to introducing the classes as the object of study together with the sample I use. As a great deal of the allomorphy we observe involving the selection of subject suffixes has to do with animacy agreement, in $\S 4$ I study in detail the verbs of the sample in the relation they hold to animacy and the suffixes they select. It then becomes clear that for the verbs with two animacy paradigms, the distribution of the suffixes selected talks about the presence of a functional

\footnotetext{
${ }^{4}$ In the 1 st and 2 nd person in (4) and in the 3rd person in (5), the suffix $-y$ is realized as an infix. When this happens, the affix is indicated within angle brackets following the Leipzig Glossing Rules convention. The reason for this infixation is given in $\S 3.1$.
} 
morphosyntactic mapping, which I develop in §5.1. In §5.2., I further suggest that when the system is taken as a whole, the default class is used to index subject agreement. Section six sums up and concludes.

\section{Overview of the verbal inflection of Lealao Chinantec.}

Lealao Chinantec is spoken in Mexico by approximately 2,000 people in the village of San Juan Lealao in the state of Oaxaca. Lealao Chinantec -called FáP ${ }^{4}-h m i{ }^{42}$ by its speakers (lit. language-Chinantec) - is one of a dozen mutually unintelligible languages that form the Chinantecan branch of Oto-Manguean; itself one of the most diverse linguistic phyla in the Americas. Lealao Chinantec is spoken at the southern borders of the Chinantla (the traditional region inhabited by the Chinantecan people), and because of this it is a geographical outlier with respect to other Chinantecan languages.

Lealao Chinantec is a typical Chinantecan language in many respects. In this section, I elaborate on two aspects of the verbal inflection of this language that are important in understanding the suffix classes as the object of the study. One is the role of tone and stress in the general making of verbal inflection, although I also mention in passing stem alternation patterns, and the other is animacy agreement.

\subsection{Prosodic inflection and stem alternation patterns.}

Chinantecan languages are tone languages. Lealao Chinantec has up to six tonal contrasts; five of which are used in inflection. Tones are linked to morae mainly in vocalic nuclei. There are twelve vowels (six oral and six nasal) and five diphthongs. Vowels can be short and long. Syllables are always open. Syllables of the type /CVP/ (e.g. stem $l a P^{42}$ in the 1SG.FUT form $i^{2}-l a ?^{42}-a^{2}$ in (4)), /CVj/ (e.g. stem plus the suffix $-y /$ nuuj ${ }^{42} /$ in the 1 SG.FUT form $P i^{2}-n u u^{42}-y$

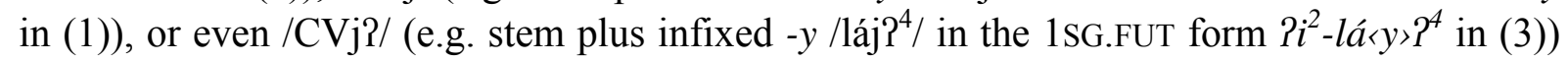
could be treated as complex nuclei. Besides tone, every syllable receives one of two phonation types, traditionally talked about in terms of stress as 'ballistic stress' (represented with an acute accent) and 'control stress' (non represented). "Ballistic syllables are characterized by an initial surge and rapid decay of intensity, with a resulting fortis articulation of the consonantal onset", while "controlled syllables generally display a more gradual surge and decay of stress, as well as a longer duration of the maximum stress." (Foris 2000: 16, but also in Rench 1978, amongst others). ${ }^{5}$

Prosodic features are exploited by the morphology to realize a great range of inflectional distinctions in verbs (and to a certain extent also in nouns). I refer to the use of such features (tone and stress type together) as 'prosodic inflection'. As an illustration of how prosodic inflection works, consider the partial paradigm in (6) for the transitive verb $P i^{2} t i \underline{u u^{2}} a^{2}$ 'spill something', (Rupp and Rupp 1996: 458).

\footnotetext{
5 The received view on ballistic stress is acoustic in nature. Alternatively, ballistic stress has also been characterized in articulatory terms as a reflection of laryngeal phonation either by an increased sub-glottal pressure in Mugele (1982) or by a laryngeal abduction in Silverman (1994).
} 
(6) $P i^{2} t i \underline{u u^{2}} a^{2}$ (tr) 'spill something'

Three grammatical tenses

\begin{tabular}{|c|c|c|c|}
\hline & PRS & PRF & FUT \\
\hline $1 \mathrm{SG}$ & tuu $-y$ & $m a^{3}-$ tuú ${ }^{4}-y$ & $\mathrm{Pi}^{2}-\underline{\text { tuu }}^{42}-\mathrm{y}$ \\
\hline $2 \mathrm{SG}$ & $\mathrm{tuu}^{3}-\mathrm{y}$ & ma $^{3}$-tiuú ${ }^{1}-y$ & $\mathrm{Pi}^{2}-\underline{\mathrm{uu}}^{3}-\mathrm{y}$ \\
\hline $3 \mathrm{SG}$ & tiuu $^{4}-\varnothing$ & $m a^{3}-$ tiuú $^{3}-\varnothing$ & ?í $^{4}$-tiuú ${ }^{4}-\varnothing$ \\
\hline 1 PL.INCL & $\operatorname{tiuu}^{42}-a^{2}$ & $m a^{3}-t i \overline{u u^{2}}-a^{2}$ & $\mathrm{Pi}^{2}-{\overline{t i u u^{2}}}^{2}-a^{2}$ \\
\hline
\end{tabular}

INFL STEMS

\begin{tabular}{|c|c|c|}
\hline INCPL & CPL & IRR \\
\hline tuu $^{4}$ & tuú $^{4}$ & $\mathrm{tuu}^{42}$ \\
\hline $\mathrm{tuu}^{3}$ & tiuú $^{1}$ & $\mathrm{tuu}^{3}$ \\
\hline tiuu $^{4}$ & tiuú $^{3}$ & tiuú $^{4}$ \\
\hline tiuu $^{42}$ & $\overline{\operatorname{tiuu}}^{2}$ & $\overline{\operatorname{tiuu}}^{2}$ \\
\hline
\end{tabular}

The linguistic literature on Chinantecan languages commonly acknowledges that the twelve cells in (6) are sufficient to derive the other cells in the paradigm through complex sets of referral rules. ${ }^{6}$ In (6), we may see that prefixes encode tense values: a bare stem is used for the tense called 'Present', $P i^{2}$ - for the 'Future' $\left(2 i^{4}\right.$ - for $\left.3 \mathrm{SG} / \mathrm{FUT}\right)$ and $m a^{3}$ - for the 'Perfect'. There are many such tenses encoded by other similar prefixes. All tenses are built on stems which are often further inflected by means of prosodic features for aspect (incompletive, completive) and mood (irrealis), sometimes also conflating information about the person-number of the subject. There are also verbs with invariant stems throughout the paradigm. Because stems play a crucial role for the verbal inflection of Lealao Chinantec, it is convenient to keep them visually separated from other inflected forms at least for some of the examples. For this reason, the inflected stems appear under the heading 'INFL STEMS'.

While the inflection of stems is carried out by prosodic features, there is no consistent one-to-one mapping between form and meaning (for details, see Baerman and Palancar, forthcoming). In other words, there is not a single tone that may be consistently associated with the realization of a specific morphosyntactic value. For example, in the inflected stems of the verb in (6) tone 4 is used for $1 \mathrm{SG} / \mathrm{INCPL}$ and $1 \mathrm{SG} / \mathrm{CPL}$, but also for $3 \mathrm{SG} / \mathrm{INCPL}$ and $3 \mathrm{SG} / \mathrm{IRR}$; tone 42 for $1 \mathrm{SG} / \mathrm{IRR}$ but also for 1PL/INCPL, etc. Similarly, ballistic stress (marked by the acute accent) is used for the CPL in all singular persons in (5), but also for 3SG/IRR. Other verbs have other prosodic patterns, and there are many of them, making verbs fall into a great number of inflectional classes defined by these prosodic distinctions (i.e. tone and ballistic stress together). Notice for instance the inflected stems of the transitive verb $P i^{2} l a ?^{1} a^{2}$ (tr) ' $\mathrm{get}$ something down' in (7) -also in (4) above- which belongs to a different prosodic class than $i^{2}$ tiuu ${ }^{2} a^{2}$ 'spill something'. I use shading in (7) to highlight the contrasts in prosody with (6).

(7) $\quad i^{2} l a ?^{1} a^{2}(\operatorname{tr})$ 'get something down'

\begin{tabular}{|c|c|c|c|c|c|c|}
\hline & PRS & PRF & FUT & INCPL & CPL & IRR \\
\hline $1 \mathrm{SG}$ & lá $\langle y\rangle ?^{4}$ & $m a^{3}-l a ́\langle y\rangle ?^{4}$ & $i^{2}-1 a ́\langle y\rangle ?^{4}$ & lá? ${ }^{4}$ & lá? & lá? \\
\hline $2 \mathrm{SG}$ & $1 a<y>?^{32}$ & $m a^{3}-1 a<y>?^{1}$ & $\mathrm{Pi}^{2}-\mathrm{lá}\langle\mathrm{y}\rangle \mathrm{P}^{2}$ & $1 a 1^{32}$ & la? ${ }^{1}$ & lá? \\
\hline $3 \mathrm{SG}$ & $1 a ?^{32}-\varnothing$ & $m a^{3}-1 a ́ ?^{2}-\varnothing$ & Pí $1^{4}-1 a ́ ?^{2}-\varnothing$ & $1 \mathrm{a}^{32}$ & lá? & lá? \\
\hline 1 PL.INCL & $1 a P^{32}-a^{2}$ & $m a^{3}-1 a ?^{1}-a^{2}$ & $\mathrm{i}^{2}-1 a ?^{1}-\mathrm{a}^{2}$ & $1 \mathrm{a}^{32}$ & la? ${ }^{1}$ & $1 \mathrm{a} ?^{1}$ \\
\hline
\end{tabular}

\footnotetext{
${ }^{6}$ Contrary to the received view, Foris (2000) stipulates that a greater number of cells involving the third person is indeed needed to reconstruct the full paradigm of a verb.
} 
Besides prosodic distinctions, verbs may further contrast in having different segmental stems in their paradigm which are arrayed in several stem alternation patterns. For this purpose compare the segmental part of the stems in the partial paradigm of the verb $2 i^{2} n i u u^{2} a^{2}(\operatorname{tr})$ 'hear something' in (8) with those of $i^{2} t i \underline{u} u^{2} a^{2}$ 'spill something' in (6), (Rupp and Rupp 1996: 457).

$P i^{2} n i u u^{2} a^{2}(\operatorname{tr})$ 'hear something'

\begin{tabular}{|c|c|c|c|}
\hline & PRS & PRF & FUT \\
\hline $1 \mathrm{SG}$ & nuu ${ }^{4}-y$ & $m^{3}-n u u^{4}-y$ & $\mathrm{Pi}^{2}-n u u^{42}-y$ \\
\hline $2 \mathrm{SG}$ & $n u u^{3}-y$ & $\mathrm{ma}^{3}-$ niuú $^{3}-\mathrm{y}$ & $\mathrm{Pi}^{2}-n u u^{3}-\mathrm{y}$ \\
\hline $3 \mathrm{SG}$ & $\mathrm{nuu}^{3}-\varnothing$ & $m a^{3}-n u u^{4}-\varnothing$ & $P^{4}{ }^{4}-$ nuú ${ }^{4}-\varnothing$ \\
\hline I PL.INCL & $n u u^{32}-a^{2}$ & $m a^{3}-$ niuu $^{2}-a^{2}$ & $\mathrm{Pi}^{2}-$ niuu $^{2}-\mathrm{a}^{2}$ \\
\hline
\end{tabular}

INFL STEMS
\begin{tabular}{|l|l|l|}
\multicolumn{1}{|c|}{ INCPL } & CPL & IRR \\
\hline nuu $^{4}$ & nuú $^{4}$ & nuu $^{42}$ \\
\hline nuu $^{3}$ & niuú $^{3}$ & nuu $^{3}$ \\
\hline nuu $^{3}$ & nuú $^{4}$ & nuú $^{4}$ \\
\hline nuu $^{32}$ & niuu $^{2}$ & niuu $^{2}$ \\
\hline
\end{tabular}

Both verbs require two stems with fundamentally the same shape: a non-palatalized one $(\underline{t u u} / n u u) v s$. a palatalized one (tiuu/niuu). However they differ in requiring the palatalized stem in different cells. Verbs like (6) use a palatalized stem for the 2SG/CPL and all aspectual stems involving 3SG and 1PL. Verbs like (8) require the palatalized stem only in three cells: 2SG/CPL, 1PL/CPL and 1PL/IRR. Such patterns are commonly independent of prosodic classes. In other words, knowing the prosodic class of a verb is generally uninformative of whether the verb undergoes stem alternations, and if it does of which type (but see Baerman, 2014a, for trends in the correlations).

\subsection{Animacy agreement.}

\subsubsection{Nouns and gender based on animacy.}

Similarly, like a Chinantecan language nouns in Lealao Chinantec fall into one of two gender classes: inanimate vs. animate. There is no morphological indication of gender class on nouns, but gender class assignment is mostly based on semantics: nouns denoting animal life, including humans, are classified as animate whereas nouns referring to other entities are inanimate. This is coherent with what is typologically expected of a gender system of this type (Corbett 1991). There are a handful of exceptions to this assignment: nouns for certain atmospheric phenomena (rainbow, lightning, meteor, etc.) and astronomic entities (sun, moon, star, etc.) are animate. ${ }^{7}$ In the nominal domain within the NP, agreement in gender may target descriptive adjectives, anaphoric deictic determiners, alienable possession markers, quantifiers and numerals. In formal terms, the encoding of inanimate agreement is left unmarked, while the forms involved in the realization of animate agreement take various forms depending on the language. In Comaltepec Chinantec, animate agreement involves nasalization of the nuclear vowel or a postnuclear nasal consonant. This is shown by the contrasts in the two examples in (9) from Anderson (1989: 56-7).

\footnotetext{
${ }^{7}$ In other Chinantecan languages like Comaltepec Chinantec (Anderson 1989: 57), inanimate nouns can be upgraded to animate to make them more salient under certain discourse circumstances.
} 
(9) Comaltepec Chinantec
a. $\quad \mathrm{e}^{\mathrm{M}} \quad h \mathrm{~h}^{\mathrm{L}}$
né: ${ }^{\mathrm{M}}$
ké: ${ }^{\mathrm{M}}$ dó ${ }^{\mathrm{M}}$
that.INAN orange(INAN) yellow.INAN of.1SG DEICT
'that yellow orange of mine'.
b. $\quad$ i $i^{\mathrm{L}} \quad$ hị ${ }^{\mathrm{L}} \quad$ nă: $\mathbf{n}^{\mathrm{M}} \quad \mathrm{ké}^{\mathrm{M}}$ dó ${ }^{\mathrm{M}}$
that.AN wasp(AN) yellow.AN of.1SG DEICT
'that yellow wasp of mine'

In Lealao Chinantec, animate marking may also involve nasalization (indicated by underlining), but for the most part the stem in animate targets also features a suffix $-y$. This is shown in (10) from Rupp (1989: 63), glosses mine.

(10) Lealao Chinantec
a. $\mathrm{ni}^{3}$
ni $^{3} \quad$ mi? $^{3} \quad$ tiaa $^{3}$
three.INAN basket(INAN) white.INAN
'Those three white baskets of mine.'
b. $\quad \mathrm{aa}^{3}-\mathbf{y}$
$\mathrm{laa}^{4}$
tieé $^{4}-\mathbf{y}$
three.AN-AN mule(AN) white.AN-AN
'Those three white mules of mine.'
kiaá ${ }^{2} \quad 2 i^{3}-n \dot{t}^{32}-\mathbf{y}$
$k e^{4} \quad P i^{3}-n \dot{r}^{3}$

The morphology involved in animacy agreement within the nominal domain involves strategies including prosodic formatives (e.g. demonstratives: $n \vec{f}^{3}$ 'that.INAN' vs. $n \vec{f}^{32}$ 'that. AN'), stem apophony (e.g. possessive relationals: $k e^{4}$ 'of.mine.INAN' VS. kiaáa 'of.mine.AN') and even occasional lexical differences (e.g. numerals: $n t^{3}$ 'three.INAN' vs. aay ${ }^{3}$ 'three.AN'), but most notably there is also the suffix $-y$ in the animate form of the adjective 'white' and in the relational element used for possession. This suffix is undoubtedly cognate of the suffix $-y$ that encodes $3 \mathrm{SG}$ in forms such as $?^{A} l a$ la $?^{4}$ 's/he'll get an animate entity down' in (5) above. This has important consequences for the understanding of the distribution of this suffix and others like it that appear in the classes of Lealao Chinantec.

\subsubsection{Animacy agreement in verbs.}

In the Chinantecan literature verbs are also talked about as agreeing in gender with one of their nominal arguments (for example, Anderson 1989, Rupp 1989, Merrifield 1968, etc.). The agreement pattern is ergative, as first pointed out explicitly by Foris (2000): intransitive verbs are said to agree in gender with their subject while transitive verbs agree with their object. ${ }^{9}$ In my opinion, the term 'gender agreement' raises expectations about the Chinantec system to be like the more canonical gender systems known in Indo-European languages

\footnotetext{
${ }^{8}$ The examples in (9) and (10) further illustrate that Chinantecan languages also differ as to targets for animate gender. This can be seen in the difference between the elements involving possession in the examples.

9 In this, like in other typological configurations like the use of a morphological inverse, Chinantecan is typologically very similar to Algonquian. Whether animacy agreement and inversion are to be treated as implicational features is an open question.
} 
where assignment is not semantically transparent for a large portion of the nominal lexicon. Because of this, I prefer using the term 'animacy agreement'.

Animacy agreement is at its clearest in verbs that inflect both as animate and inanimate depending on the animacy of one of its core arguments. For example, the intransitive verb in (10). When a verb behaves like this, I refer to it as representing an animacy pair.
(11) a. $\quad \mathrm{Pi}^{4}-\mathrm{kí} \mathrm{P}^{4}$
FUT-fall.IRR.3[3SG]
'It'll fall over.'
b. $\quad i^{4}-\mathrm{k} \dot{k}<\mathrm{y}>?^{4}$
FUT-fall.IRR.3 $<3 \mathrm{SG}>$
'He'll fall over.'

As we will see in more detail in $\S 4$, the animate and the inanimate paradigms of verbs more often than not involve differences in prosodic inflection, such as for example the case of the verb in (12).

(12) a. chiaá

[PRS]cook_in_pot.INAN.INCPL.3[3SG]

'It's cooking (i.e. the vegetable).'

b. $\quad$ chieé $^{32}-\mathrm{y}$

[PRS]cook_in_pot.AN.INCPL.3-3SG

'It's cooking (i.e. the chicken).'

When discussing examples (4-5) above, I have already pointed out that animacy agreement is important to understand the selection of the suffix classes, and I claim in $\S 5$ it plays a crucial role in keeping animate and inanimate paradigms distinct for verbs of the type in (11) and (12). In this direction, Rupp (1989:20) points out that animate agreement in intransitive verbs often involves "a syllable-final $i$ ". In reality, he is referring to cases where the affix $-y$ is used to index a 3SG animate subject as in (11b) and (12b), whereas using a bare stem (i.e., with no exponent) in (11a) and (11b) encodes $3 \mathrm{SG}$ inanimate subject. Such an analysis appears to be correct because inflected forms such as (13) are ungrammatical because they use agreement morphology which points to the wrong animacy value of the intended subject.

(13) a. * chiaá $^{3}-y$

[PRS]cook_in_pot.INAN.INCPL.3-3SG

Intended reading: 'It's cooking (i.e. the vegetable).'

b. $\quad *$ chieé $^{32}$

[PRS]cook_in_pot.AN.INCPL.3[3SG]

Intended reading: 'It's cooking (i.e. the chicken).' 
However, I will also show in $\S 4.2$ that things are far from being that clear when other verbs are involved, and for this reason I have refrained so far from using labels such as 3SG.INAN or 3SG.AN in the glosses so far.

The forms in (11) and (12) are treated in Rupp and Rupp's (1996) dictionary as instantiating two different verbal entries; that is, as being two different, but semantically and formally related, lexemes. Under this view, the differences in form we observe are accounted for as stemming from derivation (i.e., they represent lexical pairs, each with their own inflectional properties). Alternatively, in this paper I prefer to see the contrasts in (11) and (12) as representing inflected forms of two distinct paradigms of the same verbal lexeme. Under such a view, the differences in form stem from inflection (i.e., it is one lexeme whose paradigm includes cells contrasting in an animacy value).

As we will see in $\S 4$, only a portion of the Lealao Chinantec lexicon behaves like the pairs in (11) and (12). For expository purposes, I find it useful to talk about the animate and the inanimate paradigms in terms of 'animacy pairs' because the concept of 'a pair' evokes this inherent duality. Seeing the phenomenon as agreement also has advantages for the analysis I pursue in this paper, as I claim in $\$ 4.2$ that the suffix sets in (3) play an important role in keeping the morphosyntax of animacy agreement working which is particularly important for verbs with two animacy paradigms.

In this section, I presented a general overview of the inflection of verbs in Lealao Chinantec involving prosodic features and stem alteration patterns. I have also introduced the notion of animacy agreement. With this background, it seems like a good point to introduce the suffix classes in further detail.

\section{Introducing the suffix classes of Lealao Chinantec.}

\subsection{A quick look at the classes}

We have seen in $\S 1$ that the inflection of a verb in Lealao Chinantec includes a series of suffixes that Rupp (1989) analyzes as encoding the person-number of the subject. Rupp \& Rupp (1996) propose that verbs fall into the four inflectional classes given above in (3) attending to the suffix set they select. The classes in question are given in full in (14) with examples. The class Rupp \& Rupp (1996) treats as Class IV includes verbs that take $-\varnothing$ for the third person and others that take - $?$. This formal difference suggests that this Class IV can be further subdivided into two different classes, which for the moment I treat as 'Class IVa' and 'Class IVb'. All verbs in (14) appear in the future tense. ${ }^{10}$

\footnotetext{
${ }^{10}$ Verbs fall into other inflectional classes attending to the marker they select for the future tense. A group of verbs (only considering dynamic verbs) take the prefix $\imath^{2}$ - for all persons except the third person, marked by $\mathfrak{R}^{4}$-. Another large group of verbs (including stative verbs but not only) take $\imath^{4}$ - for all persons. A third class takes $d s a^{3}$ - for all persons except for the third person, which is marked by $d s a^{4}-$.
} 


$$
\begin{aligned}
& P i^{2} \tilde{n} u u^{2} a^{2}(\operatorname{tr}) \quad P i^{2} h e e^{2} a^{2}(\operatorname{tr}) \quad P i^{2} h m e e P^{2} a^{2}(\operatorname{tr}) \quad P l^{4} h i i^{42} a^{2} \text { (intr) } \quad 9 i^{4} g w i i^{32} a^{2} \text { (intr) } \\
& \text { 'tie something' 'run animate 'treat animate' 'for animate 'for animate }
\end{aligned}
$$

\begin{tabular}{|c|c|c|c|c|c|}
\hline & Class I & Class II & Class III & Class IVa & Class IVb \\
\hline $1 \mathrm{SG}$ & $\mathrm{Pi}^{2}-\tilde{\text { nuu}}-\mathrm{y}^{42}$ & $\mathrm{i}^{2}$-heé ${ }^{2}-\mathrm{a}^{4}$ & $\mathrm{Pi}^{2}-\mathrm{hmeé} \mathrm{P}^{4}-\mathrm{a}^{4}$ & ?í $^{4}-$ hii-y ${ }^{4}$ & Pí $^{4}$-gwií-y ${ }^{4}$ \\
\hline $2 \mathrm{SG}$ & $\mathrm{Pi}^{2}-\tilde{n} u u-y^{3}$ & $\mathrm{Pi}^{2}-$ heé $^{2}-\mathrm{u}^{3}$ & $\mathrm{i}^{2}-\mathrm{hmee}\langle\mathrm{y}\rangle \mathrm{P}^{1}$ & $2 i^{4}-h i i i^{4}-u^{3}$ & $P^{1} 1^{4}-g w i i^{2}-u^{3}$ \\
\hline $3 \mathrm{SG}$ & ?í $^{4}-\tilde{n} u u^{4}-\varnothing$ & ?í ${ }^{4}-$ heé-y ${ }^{2}$ & Pí $i^{4}-$ hmeé? ${ }^{4}-\varnothing$ & Pi ${ }^{4}-$ hii ${ }^{4}-\varnothing$ & $P^{\prime 4}$-gwii-? ${ }^{4}$ \\
\hline 1PL.INCL & $\mathrm{i}^{2}-\tilde{n} u u^{2}-\mathrm{a}^{2}$ & $P i^{2}-h e e^{2}-a^{2}$ & $\mathrm{ii}^{2}-\mathrm{hmee} \mathrm{P}^{2}-\mathrm{a}^{2}$ & Pí $^{4}-\mathrm{hii}^{42}-\mathrm{a}^{2}$ & $\mathrm{Pi}^{4}-\mathrm{gwii}{ }^{32}-\mathrm{a}^{2}$ \\
\hline 1PL.EXCL & $\mathrm{Pi}^{2}-\tilde{\mathrm{n}} u u^{2}-\mathrm{a} ?^{1}$ & $P i^{2}-h e e^{2}-a ?^{1}$ & $\mathrm{Pi}^{2}-\mathrm{hmee}^{2}-\mathrm{a} \mathrm{P}^{1}$ & $\mathrm{Pi}^{4}-\mathrm{hii}^{42}-\mathrm{a} \mathrm{P}^{1}$ & $\mathrm{Pi}^{4}-\mathrm{gwii}^{32}-\mathrm{a} ?^{1}$ \\
\hline 2PL & $\mathrm{Pi}^{2}-\tilde{n} u u^{3}-a ?^{3}$ & $\mathrm{ii}^{2}-$ heé $^{2}-a \mathrm{P}^{3}$ & $\mathrm{Pi}^{2}-\mathrm{hmee} \mathrm{P}^{1}-\mathrm{a} \mathrm{P}^{3}$ & $\mathrm{Pi}^{4}-\mathrm{hii}{ }^{4}-\mathrm{a} \mathrm{P}^{3}$ & $\mathrm{Pi}^{4}-g w i i^{2}-\mathrm{a} ?^{3}$ \\
\hline 3PL & $P^{4} 1^{4}-d a P^{2}-\tilde{n} u u^{4}-\varnothing$ & Pí $^{4}-\mathrm{da} ?^{2}-$ heé-y ${ }^{2}$ & Pí $^{4}-\mathrm{da} P^{2}-\mathrm{hmeé} \mathrm{P}^{4}-\varnothing$ & Pí $^{4}-\mathrm{da} \mathrm{P}^{2}-\mathrm{hii}{ }^{4}-\varnothing$ & Pi $^{4}-$ da? $^{2}$-gwii- ${ }^{4}$ \\
\hline
\end{tabular}

Before analyzing the classes in (14) further, a couple of comments about the forms are in order:

a) First, the suffix $-y$ in forms such as $P i^{2} \tilde{n} u u y^{42}$ 'I'll tie something' or $P l^{A} h e e ́ y^{2}$ 'he will run somebody over' is a palatal sonorant $/ \mathrm{j} /$ that does not receive tone. ${ }^{11}$ It also occurs in a phonological position that Rupp (1990) treats as the "post-nuclear margin'. ${ }^{12}$ When the stem has a glottalic nucleus /VP/, the combination /VPj/ (e.g. *hmee? $y^{l} * / \mathrm{me}_{\circ}: \mathrm{ij}^{1} /$ ) is not phonotactically possible, and there is metathesis of the palatal element resulting in infixation (e.g. hmee $y>?^{1} / \mathrm{me}_{\mathrm{o}} \mathrm{ij}$ ?/). ${ }^{13}$

b) The zero suffix in forms such as $2 \imath^{4} \tilde{n} u u^{4}-\varnothing$ 'he will tie something' represents a stem (i.e. $\left.\tilde{n} u u^{4}\right)$ used by its own (i.e., bare) to encode a third person.

c) Plural marking is invariant across the different classes: $-a^{2}$ for 1 PL.INCL; $-a$ ? $^{1}$ for 1PL.EXCL and $-a P^{3}$ for $2 \mathrm{PL}$. The form for $3 \mathrm{PL}$ is based on the stem used for $3 \mathrm{SG}$ and is derived from it by means of the number prefix $d a ?^{2}$ - (itself the morphologization of the plural determiner diá? ${ }^{4}$ found in NPs).

All this leaves us with the singular forms in (15) (a slightly modified version of (3) above), as the only ones which are relevant for the analysis.

\footnotetext{
${ }^{11}$ I follow in (14) Rupp and Rupp's notion of tone as a superscript that appears at the end of the syllable. This notation can give the impression that tone 42 is associated with the suffix $-y$ in forms such as $2 i^{2} \tilde{n} u u y^{42}$ ' I'll tie something', when in reality it is linked to the vocalic nucleus, i.e. $/ 2 \mathrm{i}^{2} \mathrm{nu} \mathrm{:}^{42} \mathrm{j} /$. I write tone associated with a vocalic nucleus when examples are segmented, i.e. $7 i^{2}-\tilde{n} u u^{42}-y$.

${ }^{12}$ Palatal codas are very common in lexical words (e.g. kway ${ }^{I} n a^{2}$ 'result (n)'; chiééy ${ }^{I}$ 'with', etc.).

${ }^{13}$ The elements $-y$ and $-?$ could be alternatively treated as stem extensions in the fashion of stem-based analyses such as for example the papers in Bonami (2012). However, for this particular case, such an analysis would perhaps not work on a distributional basis because the occurrence of these exponents is mutually exclusive with other more uncontroversial suffixes such as $-\hat{a}^{4},-u^{3}$, etc.
} 
Class I Class II Class III Class IV.a Class IV.b

$1 \mathrm{SG}$

$2 \mathrm{SG}$

$3 \mathrm{SG}$

\begin{tabular}{|l|l|l|l|l|}
\hline$-y$ & $-a^{4}$ & $-a^{4}$ & $-y$ & $-y$ \\
\hline$-y$ & $-u^{3}$ & $-y$ & $-u^{3}$ & $-u^{3}$ \\
\hline$-\varnothing$ & $-y$ & $-\varnothing$ & $-\varnothing$ & $-?$ \\
\hline
\end{tabular}

The classes in (15) result from the combination of the five affixes in (16) (counting - $\varnothing$ for convenience as an affix). Notice that in the mapping of form to meaning, only $-y$ is used to encode all singular persons. ${ }^{14}$

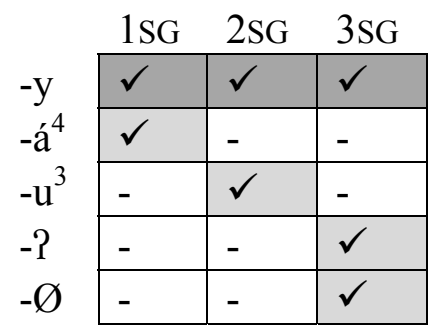

From the potential combinations of the encoding strategies in (16), we could in principle produce the 12 sets in (17), organized in four groups attending to the strategy used to encode 1SG and 2SG (i.e., $-y /-y ;-\hat{a}^{4} / u^{3} ;-\hat{a}^{4} /-y$; and $\left.-y /-u^{3}\right)$ along with three sets each attending to the marking of 3SG (i.e., $-\varnothing /-y /-?$ ). In the next section, I show that not all of these logical possibilities are indeed attested in the language.

$1 \mathrm{SG}$

$2 \mathrm{SG}$

$3 \mathrm{SG}$

\begin{tabular}{|l|l|l|}
\hline$-y$ & $-y$ & $-y$ \\
$-y$ & $-y$ & $-y$ \\
$-\varnothing$ & $-y$ & $-P$ \\
\hline
\end{tabular}

\begin{tabular}{|l|l|l|}
\hline$-a^{4}$ & $-a^{4}$ & $-a^{4}$ \\
$-u^{3}$ & $-u^{3}$ & $-u^{3}$ \\
$-\varnothing$ & $-y$ & $-?$ \\
\hline
\end{tabular}

\begin{tabular}{|l|l|l|}
\hline$-a^{4}$ & $-a^{4}$ & $-a^{4}$ \\
$-y$ & $-y$ & $-y$ \\
$-\varnothing$ & $-y$ & $-?$ \\
\hline
\end{tabular}

\begin{tabular}{|l|l|l|}
\hline$-y$ & $-y$ & $-y$ \\
$-u^{3}$ & $-u^{3}$ & $-u^{3}$ \\
$-\varnothing$ & $-y$ & $-?$ \\
\hline
\end{tabular}

\subsection{The classes in more detail.}

My analysis of the suffix classes of Lealao Chinantec is based on the study of a sample of verbs from the dictionary by Rupp \& Rupp (1996). This is a large dictionary with over 1,500 verbal entries. ${ }^{15}$ For the purposes of the present study, I have considered only 1,166 such entries. In reality, if we take each animacy pair in the dictionary to instantiate one and only one lexeme (i.e., not two), the sample consists of a total of 991 verbal lexemes. Not included in the sample are over a hundred compound verbs and a large number of stative and passive forms about which little information is given in the source.

Rupp \& Rupp (1996) provide information about class membership for each of the 1,166 entries, but for certain ones, they encode deviating behavior for 3sG. For example, for the entry of the verb $2 i^{2}$ chia $a^{4} a^{2}$ (tr) 'mix something', while the dictionary informs the user that the verb is a Class II verb, there is further warning that it also inflects as a Class I for 3sG.

\footnotetext{
${ }^{14}$ The affix for 1SG has two shapes: $-\hat{a}^{4}$ and $-\hat{a}^{2}$. Although the rules behind their distribution appear to be mostly morphophonological, it is not entirely clear in Rupp \& Rupp (1996) what the rules are for verbs. All the suffixes are used to mark possessor in nouns (p. 400). It appears that $-\hat{a}^{4}$ is the default realization, whereas $-\hat{a}^{2}$ is used when the stem has a tone $/ 1 /$ or tone $/ 42 /$.

${ }^{15}$ These data will be freely accessible online from the spring of 2015 as part of the Surrey Morphology Group databases at the University of Surrey (http://www.surrey.ac.uk/englishandlanguages/research/smg).
} 
This means that for a verb such as $2 i^{2} \operatorname{chiaa^{4}} a^{2}$, 3SG has no affixal exponent, whereas other verbs of Class II would select $-y$. I take this to mean that the verb $2 i^{2}$ chia $\underline{a}^{4} a^{2}$ belongs to a different inflectional class from Class I or Class II. To avoid the treatment of this new class as a subclass of one of the other two, I have opted to rename Rupp \& Rupp's classes altogether this time using Arabic numbers. The new notation is given in Table 1. In the table, I also give the population size of each class from a subtotal of 848 entries out of the total of 1,166 which can inflect for all persons (i.e., excluding verbs with inanimate or animal subjects). The reason why the paradigms in Table 1 are arranged in four blocks of three paradigms each is to keep it consistent with the array presented in (17).

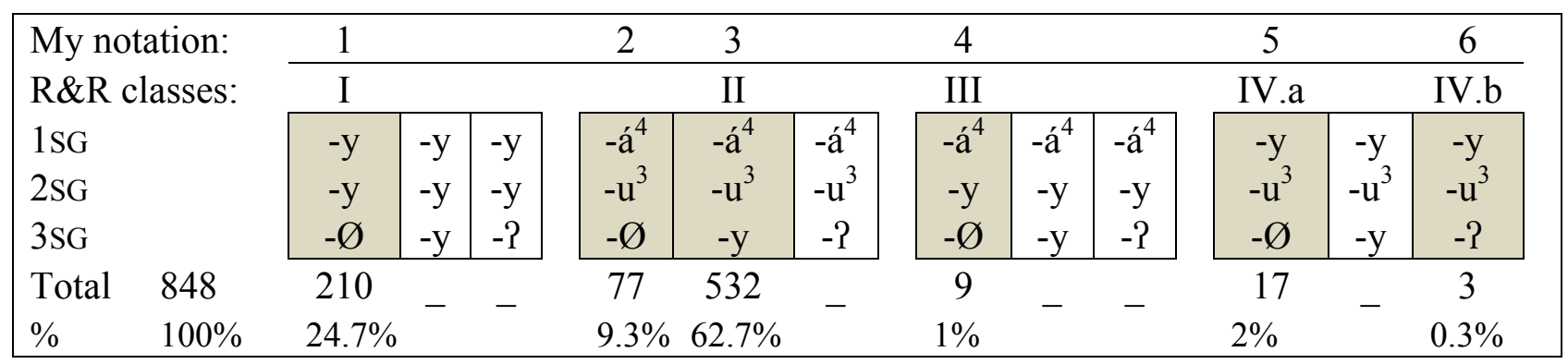

Table 1. The suffix classes of Lealao Chinantec with an indication of population size.

Table 1 shows that only certain of the logical combinations in (17) are exploited in the inflection of Lealao Chinantec verbs. $97 \%$ of the 848 verbs that inflect for all person values belong to one of three classes: 1,2 or 3 . This means that for $1 \mathrm{SG} / 2 \mathrm{SG}$ the greater bulk of the verbs either select $-y$ for both values or $-a^{4}$ and $-u^{3}$, respectively. The remaining three classes (Classes 4-6) are examples of heteroclites (Stump, 2006) because they are smaller subclasses of lexemes that recombine exponents used in other larger classes. One may also observe that $3 \mathrm{SG}$ is largely encoded without an exponent, that is, by using a bare stem, except for verbs of Class 3 and 6 which select $-y$ and -?, respectively. This means that if $-y$ is used for the 3 SG of a given verb, it can be predicted that the verb will always also select $-\hat{a}^{4}$ and $-u^{3}$ for $1 \mathrm{SG}$ and $2 \mathrm{SG}$ (i.e. no verb allows $-y$ to realize all person values). Additionally, more than half of the verbs in the sample belong to Class 3, which suggests that this class is a default from the point of view of population size.

Since Aronoff's (1994) seminal book on the autonomy of morphology, inflectional classes like the ones we observe in Table 1 are now seen as purely morphological constructs in word-and-paradigm approaches to morphology. Because of their morphological nature, inflectional classes are an interesting object of study for morphological theory, and they continue to inspire a body of work from different perspectives which is aimed at understanding their typology and internal structure, to mention just a few Ackerman et al. (2009), Baerman (2012, 2014b), Finkel \& Stump (2013), Brown \& Hippisley (2012, Chap. 3), Müller (2007) among others. Following this trend of thought and basing himself on the principles of canonical typology laid out in Corbett (2007), Corbett (2009) argues that a canonical inflectional class is not be motivated by any other levels of grammar. This lack of motivation makes inflectional classes useless in functional terms, and in being so, they introduce a layer of morphological complexity into the inflectional system which speakers need to contend with (Baerman et al. 2010, Baerman 2013a). However, in order to be able to assert that classes such as the ones in Lealao Chinantec constitute a case of morphological 
allomorphy, one needs to explore possible motivations and evaluate the degree of their impact on the system as a whole. One obvious place to start is the phonology.

In this direction, I have not been able to find pairs of verbs belonging to the major classes with a homophonous stem. Even if I had (or if such cases existed), the homophony should in any case be handled with caution because the citation forms in the dictionary are themselves inflected forms (i.e. mostly 1st person plural future, but also 3rd person singular for inanimate verbs). As verbal inflection is made up of prosodic classes and stem alternations, the prosodic and segmental features in the entries themselves often reflect inflectional distinctions of their respective paradigms, and only after careful scrutiny one may end up having comparable phonological shapes to study prosodic features at a lexical level.

Nevertheless, one may still scan a representative list of partial homophones such as the list of entries in (18) to test if the phonology gives us clues as to the selection of at least some of the allomorphy in Table 1. For consistency, all examples in (18) represent 1st person plural future forms.

\begin{tabular}{|c|c|c|c|}
\hline $\begin{array}{c}\text { 1PL.FUT } \\
\mathrm{Pi}^{2} \text {-chiaa }{ }^{42}-\mathrm{a}^{2}\end{array}$ & 'We'll keep it' & (tr., inanimate object) & Class 1 \\
\hline $\mathrm{Pi}^{2}-$ chiaá $^{4}-\mathrm{a}^{2}$ & 'We'll mix it' & (tr., inanimate object) & Class 2 \\
\hline $\mathrm{Pi}^{2}-P e \mathrm{P}^{42}-\mathrm{a}^{2}$ & 'We'll burp' & (intr., animate subject) & Class 1 \\
\hline $\mathrm{Pi}^{2}-\mathrm{Peé}^{4} \mathrm{P}^{-} \mathrm{a}^{2}$ & 'We'll nail it' & (tr., inanimate object) & Class 2 \\
\hline$P i^{2}-n i u u^{2}-a^{2}$ & 'We'll listen to it' & (tr., inanimate object) & Class 1 \\
\hline $\operatorname{li}^{2}-$ niuú $^{4}-a^{2}$ & 'We'll mud it up' & (tr., inanimate object) & Class 2 \\
\hline$P i^{2}-\operatorname{taa}^{42}-a^{2}$ & 'We'll chop it' & (tr., inanimate object) & Class 1 \\
\hline$P i^{2}-t a a^{3}-a^{2}$ & 'We'll believe it' & (tr., inanimate object) & Class 2 \\
\hline$P i^{2}-t i \underline{a a}^{2}-a^{2}$ & ‘We'll help him’ & (tr., animate object) & Class 1 \\
\hline$P i^{2}-$ tiaa $^{42}-a^{2}$ & 'We'll mend it' & (tr., inanimate object) & Class 2 \\
\hline$P i^{2}-\operatorname{sit}^{42}-a^{2}$ & 'We'll dip it in sauce' & (tr., inanimate object) & Class 1 \\
\hline $\operatorname{Pi}^{2}-\operatorname{sith}^{4}-a^{2}$ & 'We'll gnaw it' & (tr., inanimate object) & Class 2 \\
\hline $\mathrm{Pi}^{2}-\mathrm{xaa} ?^{2}-\mathrm{a}^{2}$ & 'We'll grab it for him' & (dtr., inanimate object) & Class 1 \\
\hline$i^{2}-x a a^{32}-a^{2}$ & 'We'll be rich' & (intr., animate subject) & Class 2 \\
\hline
\end{tabular}

In all the contrastive pairs in (18) -except those in (e) and (g) - the stem of a Class 2 verb carries ballistic stress (indicated by the acute accent), while all Class 1 stems carry control stress. How shall we interpret this? We can take stress distinction as a possible motivating factor for the allomorphy. Restricting ourselves for consistency to the stems in 812 citation forms instantiating 1st person plural future forms in the three major classes, the correlations involving ballistic/control stress we obtain are given in Table 2. 


\begin{tabular}{|l|lll|}
\hline \multicolumn{5}{c}{} & $\begin{array}{l}\text { Ballistic stress } \\
\text { in }\{1 \text { PL, FUT }\}\end{array}$ & $\begin{array}{l}\text { Controlled stress } \\
\text { in \{1PL, FUT }\}\end{array}$ & Total \\
\cline { 2 - 4 } Class 1 & $\mathbf{3}$ & 207 & 210 \\
& $\mathbf{1 . 4 \%}$ & $98.6 \%$ & $100 \%$ \\
\cline { 2 - 4 } Class 2 & 37 & 37 & 74 \\
& $50 \%$ & $50 \%$ & $100 \%$ \\
\cline { 2 - 4 } Class 3 & 156 & 372 & 528 \\
& $29.5 \%$ & $70.5 \%$ & $100 \%$ \\
\hline
\end{tabular}

Table 2. Correlations involving stress type and forms for $\{1 \mathrm{PL}, \mathrm{FUT}\}$.

The figures in Table 2 suggest that if a verb belongs to Class 1, it has controlled stress at least for the form of the 1st person plural future. Alternatively, one can say the same differently. If the form for 1st person plural future has ballistic stress, the verb is NOT of Class 1 (except for three verbs). Beyond this point, phonology does not help us further.

I have pointed out in $\$ 2.2 .2$ that the morphology involved in the classes has to do with the dimension of animacy. In this light, the obvious next step to take is visit the sample of verbs according to their inflectional behavior with respect to this dimension. This is what I do in the next section where I show that there are indeed correlations, to such an extent that for verbs with two animacy paradigms there is a fully functional morphosyntactic mapping involving a mixed agreement system of person-number of subject S/A with animacy of S/O.

\section{The verbs in the sample and their relation to animacy.}

The verbs in the sample could be said to fall into two main groups. In one group, we find verbs that can be inflected animate or inanimate attending to agreement in animacy with the $\mathrm{S} / \mathrm{O}$ argument. I refer to such verbs as 'paired-verbs'. The other group is formed by verbs that can only be animate or inanimate, which I call 'non-paired verbs'. Table 3 gives an indication of the population size of the two groups in the sample attending to verbal entries. ${ }^{16}$

\begin{tabular}{|c|c|c|c|c|c|c|}
\hline & $\begin{array}{r}\text { non- } \\
8\end{array}$ & ired & $\begin{array}{c}\text { paired } \\
175 \text { lexemes } \\
(=350 \text { entries }) \\
\text { inanimate/animate }\end{array}$ & Lex. & $\begin{array}{l}\text { otal } \\
\text { Entries }\end{array}$ & \\
\hline intr/S & 226 & 212 & $\begin{array}{c}53 \\
106 \text { entries }\end{array}$ & 491 & 544 & $\begin{array}{l}\text { Lex. } \\
\text { Entries }\end{array}$ \\
\hline $\operatorname{tr} / \mathrm{O}$ & 257 & 121 & $\begin{array}{c}122 \\
244 \text { entries }\end{array}$ & 500 & 622 & $\begin{array}{l}\text { Lex. } \\
\text { Entries }\end{array}$ \\
\hline Total & 483 & 333 & $\begin{array}{c}175 \\
350 \text { entries }\end{array}$ & 991 & 1,166 & $\begin{array}{l}\text { Lex. } \\
\text { Entries }\end{array}$ \\
\hline
\end{tabular}

Table 3. Verbs in the sample attending to their ability to enter in animacy pairs.

\footnotetext{
${ }^{16}$ There are a few entries in the dictionary I have opted to classify as non-paired verbs because the stem of the animate entry has a prefix $\boldsymbol{b i}{ }^{3}$ - and appears derived, e.g. $2 i^{2}-b i^{3}-n a^{4} a^{2}$ 'for someone to be absent' vs. $2 \imath^{4} n \hat{a}^{4}$ 'something lacking'; or $P i^{2}-b i^{3}-c a a^{l} a^{2}$ 'play with someone' vs. $P i^{4} c a a{ }^{42} a^{2}$ 'play with something'; $P i^{2}-b i^{3}-P i n P^{42} a^{2}$ 'forget someone' vs. $P t^{4}-\left\{i n ?^{4}\right.$ 'forget something'; or $P i^{2}-b i^{3}-f i t^{1} a^{2}$ 'increase the amount of an animate entity' vs. $? i^{2}-f i t^{42}-a^{2}$ 'pile up something'. This prefix also appears in the stems of some paired verbs.
} 
Let us see these verbs in more detail investigating their animacy value in relation to their prosodic inflection and the suffix class they select. I introduce first non-paired verbs where I show that the system points out remnants of a motivated core involving animacy agreement, which is still functional with paired verbs.

\subsection{Non-paired verbs.}

\subsubsection{Non-paired verbs, prosodic inflection and animacy.}

In general, when one studies these verbs it is difficult, if not utterly impossible, to determine whether a given one is inanimate or animate if one were to just look at the prosodic features of its inflection. This is because the verbs in Lealao Chinantec can fall into a very large number of prosodic classes, with many such classes having only one member. To show the (absence of) correlations between prosodic inflection and animacy, I compared the prosodic marking involved in all non-paired. Following Baerman and Palancar (forthcoming) that propose that in Chinantec verbal inflection it is convenient to deal with 3rd person forms independently from the inflection of other persons, I have treated the different classes involved in the marking of a 3rd person apart from the classes used to encode other person values (i.e., 1SG, 1PL, 2). The actual forms used for these many prosodic classes are given in the Appendix. The verbs in classes labeled /1/,/2/, etc. all belong to one large class which does not have prosodic inflection. The notation for these verbs indicate the actual phonology of the stem -the apostrophe indicates ballistic stress. I have included them here to show that lexical phonology of a given stem is not really informative about animacy value. I use shading in the table to highlight prosodic classes aligned with a specific animacy value. ${ }^{17}$

\footnotetext{
${ }^{17}$ The angle bracket $>$ indicates an 'act on'-type of transitive relation between an A argument and an $\mathrm{O}$ argument, it should for example be read as ' $1 \mathrm{SG} / 2 / 1 \mathrm{PL}$ act on INAN O'.
} 


\begin{tabular}{|c|c|c|c|c|c|c|c|c|}
\hline \multirow[t]{2}{*}{$\mathrm{Cl}$. } & \multicolumn{2}{|c|}{3} & \multirow[t]{2}{*}{$\mathrm{Cl}$. } & \multicolumn{2}{|c|}{$1 \mathrm{SG} / 2 / 1 \mathrm{PL}$} & \multirow[t]{2}{*}{$\mathrm{Cl}$. } & \multicolumn{2}{|c|}{$1 \mathrm{SG} / 2 / 1 \mathrm{PL}$} \\
\hline & INAN & AN & & $>$ INAN & $>\mathrm{AN}$ & & $>$ INAN & $>\mathrm{AN}$ \\
\hline \multirow{6}{*}{$\begin{array}{l}a \\
b\end{array}$} & & 2 & \multirow[b]{2}{*}{2} & 20 & 24 & 37 & 1 & \\
\hline & 2 & & & 9 & 7 & 38 & 1 & 1 \\
\hline & 1 & 2 & \multirow{2}{*}{$\begin{array}{l}3 \\
4\end{array}$} & 3 & 1 & 39 & & 2 \\
\hline & 2 & 2 & & & 1 & 40 & 2 & \\
\hline & 1 & & \multirow[t]{2}{*}{5} & 40 & 17 & 41 & & 2 \\
\hline & & 1 & & 12 & 33 & \multirow{2}{*}{$\begin{array}{l}42 \\
43\end{array}$} & 1 & \\
\hline$g$ & 25 & 6 & 7 & 22 & 4 & & & 1 \\
\hline$h$ & 1 & 1 & 8 & 17 & 16 & 44 & & 2 \\
\hline \multirow{2}{*}{$\begin{array}{l}i \\
j\end{array}$} & & 1 & \multirow{2}{*}{$\begin{array}{l}9 \\
10\end{array}$} & 16 & 2 & \multirow{2}{*}{$\begin{array}{l}45 \\
46\end{array}$} & 2 & \\
\hline & & 1 & & 17 & 1 & & 1 & \\
\hline$k$ & 2 & 1 & \multirow{2}{*}{$\begin{array}{l}11 \\
12\end{array}$} & 3 & 8 & 47 & & 1 \\
\hline$l$ & 115 & 53 & & & 16 & 48 & & 1 \\
\hline$m$ & 1 & & 13 & 1 & 3 & 49 & 1 & \\
\hline$n$ & 4 & 1 & 14 & & 9 & 50 & & 1 \\
\hline$o$ & 9 & 1 & 15 & 1 & 5 & 51 & & 1 \\
\hline$p$ & & 1 & 16 & 3 & 2 & 52 & 1 & \\
\hline$q$ & 32 & 15 & 17 & 4 & 3 & 53 & 1 & \\
\hline$r$ & 1 & 1 & 18 & 2 & 2 & 54 & 1 & \\
\hline /1/ & 4 & 10 & 19 & 3 & 0 & 55 & 1 & \\
\hline ו'ו'ו & 14 & 17 & 20 & 7 & 2 & 56 & 1 & \\
\hline 121 & 10 & 1 & 21 & 5 & 2 & 57 & & 1 \\
\hline /'2/ & 23 & 13 & 22 & 1 & 1 & 58 & 1 & \\
\hline 131 & 48 & 41 & 23 & & 5 & 59 & & 1 \\
\hline /'3/ & 70 & 46 & 24 & & 1 & 60 & & 1 \\
\hline $132 /$ & 2 & 12 & 25 & & 5 & 61 & 1 & \\
\hline 141 & 37 & 35 & 26 & 3 & 2 & $q$ & 1 & 2 \\
\hline I'4/ & 72 & 63 & 27 & & 3 & $l$ & 1 & 14 \\
\hline $142 /$ & 7 & 6 & 28 & & 3 & $/ 1 /$ & 1 & 9 \\
\hline Total & 483 & 333 & 29 & 4 & & /'ון & 2 & 4 \\
\hline & & & 30 & 2 & 2 & 121 & & 1 \\
\hline & & & 31 & 1 & 2 & /'2/ & & 6 \\
\hline & & & 32 & 1 & & /'3/ & 3 & 18 \\
\hline & & & 33 & 2 & 1 & $132 /$ & 1 & 11 \\
\hline & & & 34 & & 1 & /'4/ & 23 & 36 \\
\hline & & & 35 & 1 & & $142 /$ & 3 & 3 \\
\hline & & & 36 & 2 & & (without non-3 & 230 & 30) \\
\hline & & & & & & Total & 483 & 333 \\
\hline
\end{tabular}

Table 4. Prosodic classes in non-paired verbs contrasting inanimate vs. animate. 
Table 4 shows that verbs belong to 19 classes to inflect for a 3SG, but many such classes have only one verb. Excluding those, there are only two (i.e., $a$ and $b$ ) which are specific to inanimates but they have only two members each, so again they are utterly irrelevant. We can conclude that the form for the 3rd person does not help much in predicting animacy. Exactly the same can be broadly said for the forms inflected in other persons of which we have up to 64 classes, most of them instantiated by one or two verbs. Classes 12 (with 16 members) and 14 (with nine) are the most notable exception as they only include animates. The system does not seem to like absolutes, but there are tendencies. For example a verb that inflects like a class $l$ for the 3rd person is likely to be inanimate, but if the verb inflects for the other persons in this class, it is likely to be animate. Likewise, it is highly probable that a verb with no prosodic inflection whose stem bears the prosodic feature //3/is animate.

If prosody is not a good indicator of animacy value, this opens the possibility that the morphology in the suffix classes is perhaps used for this purpose. I entertain this hypothesis in the following sections, where I claim that this is precisely what happens, at least with animate verbs; inanimate ones appear to have a more canonical inflectional class distribution.

\subsubsection{Non-paired verbs and the suffix classes.}

The distribution of the 816 non-paired attending to class membership is given in Table 5. In order to present the data in a more convenient way, I have extracted Class 3 to the left.

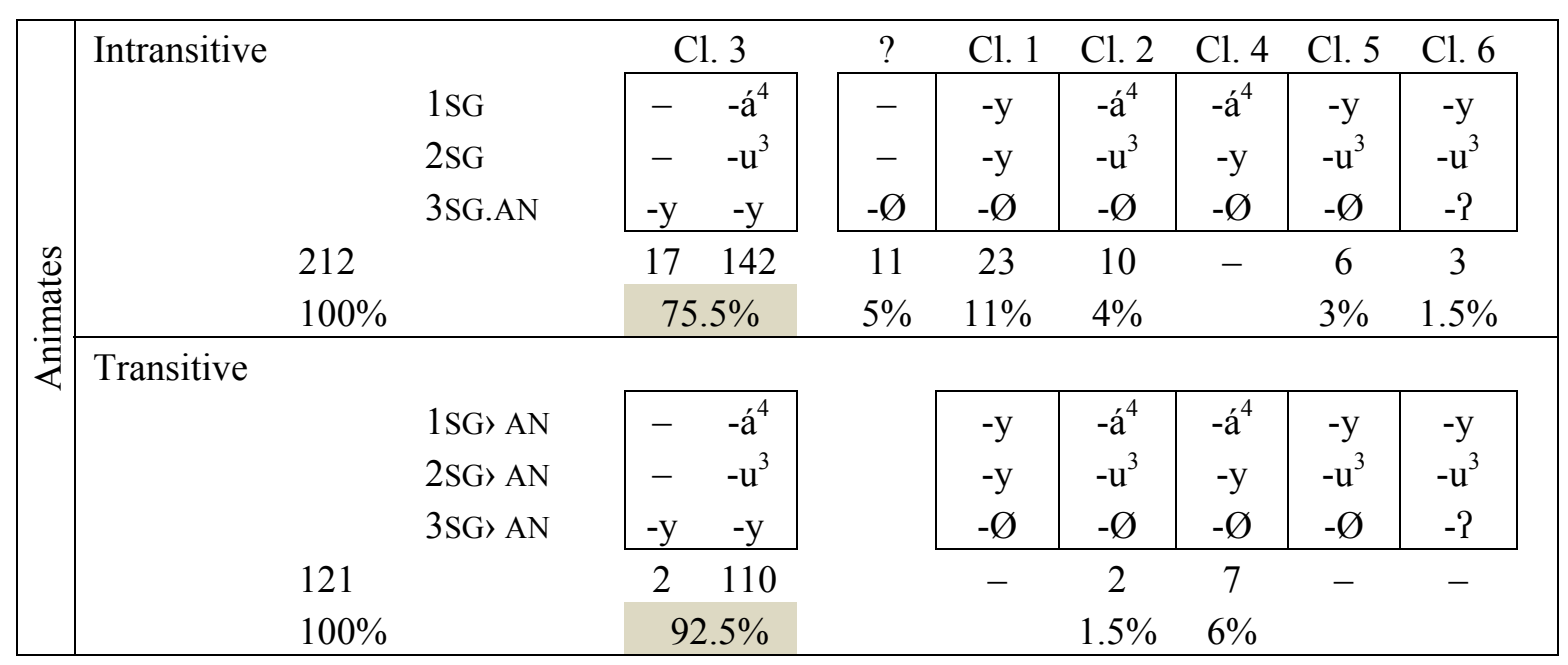




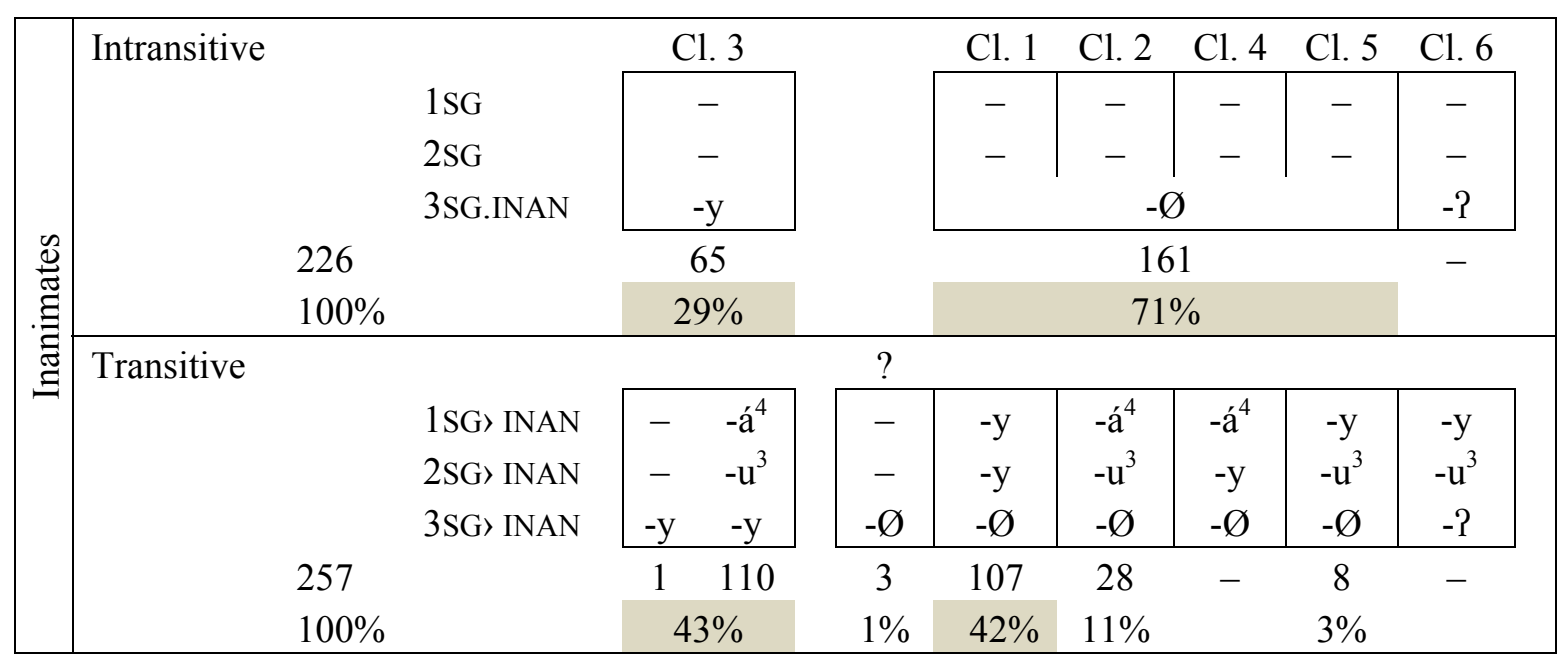

Table 5. The 816 non-paired verbs of the sample.

The data in the Table 5 show two different, but related things: (i) animate verbs have a clear preference to belong to Class 3; and (ii) many of the members of Class 1 are inanimate verbs. This could suggest that the suffixes of these classes $\left(-a^{4},-u^{3},-y\right.$ and $\left.-y,-y,-\emptyset\right)$ are used to indicate animacy information about their respective $\mathrm{S} / \mathrm{O}$ arguments in such a way that in an ideal state of affairs, Class 3 would say something about S/O being animate and Class 1 , used with transitives, that $\mathrm{O}$ is inanimate. However, a closer look at the table further reveals that in reality things are a bit messier: (iii) almost half of the inanimate verbs also belong to Class 3 ; and (iv) a score of animate verbs are also found in Class 1. This situation suggests that the system we observe in Lealao Chinantec has some motivated core, while still displaying inflectional class organization. In this, the Chinantec system is typologically very similar to other better known inflectional class systems found in Indo-European languages which are partly motivated by gender. I address this commonalty in $\S 5.2$.

Before observing paired verbs in the next section and proposing what the morphosyntax of this core is in $\S 5.1$, I think it is first worth studying whether the exceptions in (iii) and (iv) could be accounted for by other means. To address the issue raised in (iii), I study the 49 intransitive animate verbs that use a bare stem to encode a 3rd person -largely a coding strategy for inanimates- under the hypothesis that perhaps these verbs have some semantic property in common that make them stand out from the rest of animate verbs. For this purpose consider Table 6, where I have arrayed such verbs in different semantic fields (like most animate verbs, the verbs in question appear in their citation form in the 1st person plural future). 


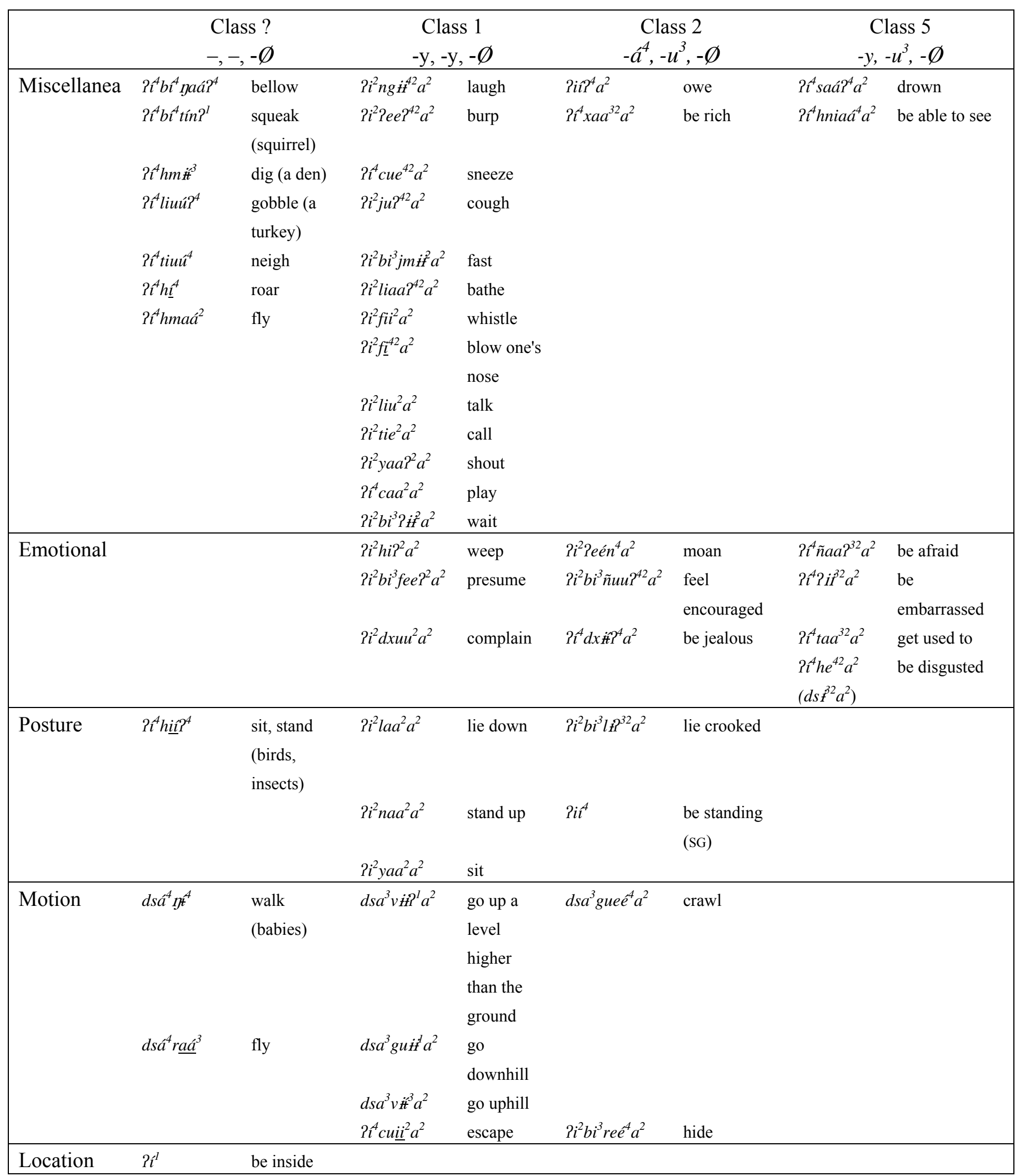

Table 6. The 49 intransitive animate non-paired verbs that do not belong to Class 3 . 
When one observes the semantics of the verbs in Table 6, it is difficult to come up with a semantic property that unites all these lexemes into one coherent group. It is true that some of those in Class 1 depict activities some of which are typically found in fluid systems with semantic alignment of the agentive/patientive type, e.g. 'laugh', 'burp', 'sneeze', etc. Others are more agentive 'talk', 'whistle', 'shout', 'play', etc. But similar verbs are also largely found in Class 3. It is equally difficult to predict how an intransitive animate verb will be inflected if we were to be led only by the semantics, as verbs with very similar meanings are found in different classes (e.g. $P i^{2} l a a^{2} a^{2}$ 'lie down', $P i^{2} h i{ }^{2} a^{2}$ 'weep' and $P l^{4}$ cuiin $^{2} a^{2}$ 'escape' are of Class 1 , but $P i^{2} b i^{3} l \hat{\imath} P^{32} a^{2}$ 'lie crooked' and $P i^{2} P e e n^{4} a^{2}$ 'moan' and $P i^{2} b i^{3} r e e^{4} a^{2}$ 'hide' are of Class 2, while having very similar semantic). Admittedly, the first column in Table 6 could give the impression that verbs referring to actions performed by animals receive $-\varnothing$ instead of $-y$ for the 3rd person, but there are also verbs depicting animal actions that belong to Class 3 , as for example the ones in Table 7.

\begin{tabular}{|c|c|}
\hline & $\begin{array}{l}\text { Class } 3 \\
-,-,-y\end{array}$ \\
\hline$P \imath^{A} b \imath^{A} c \ddot{x} y^{1}$ & growl (animal) \\
\hline Pit féy ${ }^{4}$ & flap wings \\
\hline Pînieéy ${ }^{1}$ & be tied up (an animal) \\
\hline Pînát chieey ${ }^{42}$ & gather up together (animals) \\
\hline$P i^{4} n a^{4} c u a a y ?^{42}$ & gather up together (animals) \\
\hline$P l^{4} c \dot{y} y P^{42}$ & fall (animal) \\
\hline$P \imath^{4} y a^{4}$ niuuy? $?^{4}$ & go around broody (a hen) \\
\hline Pit nieey $^{4}$ & shed skin (a serpent) \\
\hline$P^{4} v \ddot{t} y ?^{2}$ & be born (of an egg) \\
\hline$d s a^{4} x u^{4} l a ́ y P^{4}$ & scratch off (animal) \\
\hline$P^{4} \mathbf{s i m y}^{3}$ & be sullen (animal) \\
\hline Pitchiéy? ${ }^{4}$ & shake (animal) \\
\hline
\end{tabular}

Table 7. Animate intransitive verbs of Class 3 referring to actions of animals.

Finally, if such verbs where to be inflected in $1 \mathrm{SG}$ or $2 \mathrm{SG}$ (as characters speaking in a fable), it is not entirely sure what the suffix selected would be. The list in Table 6 suggests that it would be by means of $-y$ for either value, imagining the verb could be interpreted as a Class 1 verb. But the existence of the verb $d s a^{3} g u e e^{-4} a^{2}$ 'crawl' in Class 2 (which we can compare with the verb $d s a^{4} n g{ }_{t}^{4}$ 'for a baby to be able to walk') together with the list in Table 7 further suggests that it could just as well be by means of $-a^{4}$ and $-u^{3}$. From all this, we can conclude that semantics does not help in determining class membership, at least for the intransitive verbs considered.

Before moving on to paired verbs in the next section, let us address issue (iv) by considering the inanimate verbs that belong to Class 3. For these verbs, we could entertain the hypothesis that their receiving suffixes $-a^{4},-u^{3},-y$ is because their prosodic inflection is similar to the animate verbs of Class 3 , but different from those of Class 1 . We have seen in Table 4 above that prosodic inflection is largely uninformative about animacy, but it could happen that verbs that receive the same prosodic inflection would attract similar sets of suffixes. If this were the case, the selection of Class 3 suffixes by inanimate verbs would be 
accounted for as being conditioned by the type of prosodic inflection the verb receives, and hence it would be linked to the phonology of the inflected stem. For this purpose, I have compared the prosodic inflection of the 110 inanimate transitive verbs of Class 3 on the one hand with the 105 inanimate transitive verbs of Class 1 and on the other with the 109 animate transitive verbs of Class 3 . The results are given in Table 8 .

\begin{tabular}{|c|c|c|c|c|c|c|c|c|c|c|c|}
\hline \multirow{4}{*}{ Cl. } & \multicolumn{3}{|c|}{3} & & \multicolumn{3}{|c|}{$1 \mathrm{SG} / 2 / 1 \mathrm{PL}$} & & \multicolumn{3}{|c|}{$1 \mathrm{SG} / 2 / 1 \mathrm{PL}$} \\
\hline & \multicolumn{2}{|c|}{ INAN } & \multirow{2}{*}{ AN } & & \multicolumn{2}{|c|}{ INAN } & \multirow[t]{2}{*}{ AN } & & \multirow{2}{*}{ INAN } & \multicolumn{2}{|c|}{ AN } \\
\hline & Cl. 1 & Cl. 3 & & \multirow{2}{*}{$\begin{array}{l}C l \\
l\end{array}$} & \multirow[t]{2}{*}{ Cl. 1} & Cl.3 & & $\mathrm{Cl}$ & & Cl. 1 & Cl.3 \\
\hline & & & 2 & & & 14 & 22 & 31 & & 1 & \\
\hline \multirow{2}{*}{$\begin{array}{l}b \\
d\end{array}$} & 2 & & & 2 & & 4 & 7 & \multirow{2}{*}{$\begin{array}{l}32 \\
35\end{array}$} & 1 & & \\
\hline & & 2 & \multirow[t]{2}{*}{1} & 3 & & 3 & 1 & & & 1 & \\
\hline$g$ & 23 & & & 5 & & 39 & 16 & 36 & 2 & & \\
\hline$k$ & 2 & & & 6 & & 11 & 13 & \multirow{2}{*}{$\begin{array}{l}37 \\
40\end{array}$} & 1 & & \\
\hline$l$ & 53 & 36 & 29 & 7 & 22 & & & & 2 & & \\
\hline$n$ & & & 1 & 8 & 6 & 11 & 1 & 41 & & & 2 \\
\hline \multirow[t]{2}{*}{$o$} & 9 & & & 9 & 16 & & & \multirow{2}{*}{$\begin{array}{l}42 \\
45\end{array}$} & 1 & & \\
\hline & 4 & 1 & 8 & 10 & 17 & & & & 2 & & \\
\hline $\begin{array}{l}q \\
r\end{array}$ & & 1 & & 11 & & 3 & 6 & 46 & 1 & & \\
\hline /1/ & & 1 & 2 & 13 & & & 3 & 49 & 1 & & \\
\hline /'I & 1 & 3 & 2 & 14 & & & 9 & 53 & 1 & & \\
\hline /2/ & 2 & & & 15 & & 1 & 5 & 54 & 1 & & \\
\hline /'2/ & 1 & 4 & 6 & 16 & 3 & & & 55 & 1 & & \\
\hline /3/ & 3 & 15 & 18 & 17 & 4 & & & 56 & 1 & & \\
\hline /'3/ & 3 & 16 & 23 & 18 & & 2 & 2 & 58 & 1 & & \\
\hline 132/ & & 2 & 1 & 19 & 3 & & & $q$ & & 1 & \\
\hline /4/ & & 6 & 9 & 20 & 7 & & & $l$ & & 1 & 1 \\
\hline |'4/ & 4 & 20 & 6 & 21 & 5 & & 2 & $/ 1 /$ & & 1 & 2 \\
\hline 142/ & & 3 & 2 & 24 & & & 1 & /'l/ & & 2 & 1 \\
\hline Total & 107 & 110 & 110 & 25 & & & 5 & $/ / 3 /$ & & 2 & 1 \\
\hline & & & & 26 & 3 & & & $132 /$ & & 1 & 1 \\
\hline & & & & 28 & & & 2 & /'4/ & 1 & 7 & 4 \\
\hline & & & & 29 & 4 & & & $142 /$ & & 3 & 2 \\
\hline & & & & 30 & & 2 & 1 & & & & \\
\hline & & & & & & & & Total & 107 & 110 & 110 \\
\hline
\end{tabular}

Table 8. Transitive verbs of Class 1 and 3 compared for prosodic features.

Table 8 shows that there are formal similarities between the animate and the inanimate verbs of Class 3. This is puzzling because prosodic inflection appears to align with animacy on the one hand, while on the other it aligns with class. In this respect, there is for example a tendency for the inanimate verbs of Class 1 to take a different inflection than the animate verbs of Class 3, and hence prosody aligns with animacy value. But the verbs of Class 3 that are inanimate take a similar inflection than animate verbs, and hence prosody aligns with class. One way to understand this situation and the reason why we have transitive inanimate 
verbs in Class 3 is to regard this class as a default (in the sense of the 'elsewhere' case) that bears its own distinctive prosodic properties associated with it. In this light, Class I would have to be seen as a subclass within this major class (see $\S 5.2$ for more arguments in favor of Class 3 as a default).

\subsection{Paired verbs}

\subsubsection{Paired verbs, prosodic inflection and animacy.}

Paired-verbs are verbs that inflect as both animate and inanimate depending on the animacy of their S/O argument. In Rupp and Rupp's (1996) dictionary, I have been able to identify 175 such verbs: 53 intransitive and 122 transitive. For the intransitive verbs, only the forms for the 3rd person are comparable, because in natural usage the inanimate paradigm of the verb cannot have forms for other persons. To inflect for animacy agreement, a verb often belongs to different prosodic classes simultaneously. When it does, there are two main patterns.

In the first pattern, the animate paradigm has different tonal inflection than the inanimate one. There are 67 paired verbs that behave like this. The example in (19) illustrates an intransitive verb with its two paradigms, and that in (20) a transitive one.

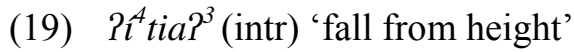

a. INAN 'for something to fall from height'

INFL STEMS

\begin{tabular}{ll|l|l|}
\multicolumn{1}{c}{} & \multicolumn{1}{l}{ PRS } & \multicolumn{1}{l}{ PRF } & \multicolumn{1}{l}{ FUT } \\
\cline { 2 - 4 } 3SG.INAN & tia? $^{3}$ & ma $^{3}$-tia? $^{3}$ & Pí $^{4}-$ tia? $^{3}$ \\
\cline { 2 - 3 } & &
\end{tabular}

\begin{tabular}{|l|l|l|}
\multicolumn{1}{|l}{ INCPL } & CPL & \multicolumn{1}{l}{ IRR } \\
\hline tia? $^{3}$ & tia? $^{3}$ & tia? $^{3}$ \\
\hline
\end{tabular}

b. AN 'for animate entity to fall from height'

INFL STEMS

\begin{tabular}{|c|c|c|c|}
\hline & PRS & PRF & FUT \\
\hline $1 \mathrm{SG}$ & $\operatorname{tia}^{4}-a^{4}$ & $m^{3}$-tiá? ${ }^{3}$-a $^{4}$ & $\mathrm{Pi}^{4}-\mathrm{tiá}^{4}{ }^{4}-a^{4}$ \\
\hline $2 \mathrm{SG}$ & $\operatorname{tia}^{4}-u^{3}$ & $m a^{3}-$ tiá$^{3} \mathrm{u}^{3} \mathrm{u}^{3}$ & $\mathrm{Pi}^{4}-\mathrm{tiá} \mathrm{P}^{4}-\mathrm{u}^{3}$ \\
\hline 3SG.AN & tia<y>? ${ }^{4}$ & $m^{3}-$-tiá $\left\langle y>?^{3}\right.$ & $P^{4} 1^{4}$ tiá $\langle y\rangle ?^{4}$ \\
\hline 1PL.INCL & $\operatorname{tia}^{4}-\mathrm{a}^{2}$ & $m a^{3}-$ tiá $^{3}{ }^{3}-a^{2}$ & ${ }^{1} 1^{4}-t i a ́{ }^{4}-a^{2}$ \\
\hline
\end{tabular}

\begin{tabular}{|l|l|l|}
\multicolumn{1}{l|}{ INCPL } & \multicolumn{1}{c}{ CPL } & \multicolumn{1}{c|}{ IRR } \\
\hline tia? $^{4}$ & tiá $^{3}$ & tiá$^{4}$ \\
\hline tia? $^{4}$ & tiá $^{3}$ & tiá$^{4}$ \\
\hline tia? $^{4}$ & tiá$^{3}$ & tiá$^{4}$ \\
\hline tia? $^{4}$ & tiá$^{3}$ & tiá$^{4}$ \\
\hline
\end{tabular}

(20) Pi $^{4} l i a ?^{2}$ (tr) 'push'

a. INAN 'push something'

\section{INFL STEMS}

\begin{tabular}{|c|c|c|c|}
\hline & PRS & PRF & FUT \\
\hline $1 \mathrm{SG} \gg \mathrm{INAN}$ & $\operatorname{lia}\langle y\rangle ?^{4}$ & $\mathrm{ma}^{3}$-liá<y $>?^{4}$ & $2 i^{2}-1 i a\langle y\rangle ?^{42}$ \\
\hline $2 \mathrm{SG} \gg \mathrm{INAN}$ & $\operatorname{lia}\langle y\rangle ?^{3}$ & $m^{3}-$ liá $\langle y\rangle ?^{1}$ & $2 i^{2}-1 i a\langle y\rangle ?^{3}$ \\
\hline $3 \mathrm{SG} \gg \mathrm{INAN}$ & $\operatorname{lia?}^{4}$ & $\mathrm{ma}^{3}$-liá? ${ }^{3}$ & Pít$^{4}-1 i a{ }^{4}$ \\
\hline $1 \mathrm{PL}>\mathrm{INAN}$ & $\operatorname{lia}^{42}$ & $\mathrm{ma}^{3}-\mathrm{lia} ?^{2}$ & Pí $^{4}-1 i a ?^{2}$ \\
\hline
\end{tabular}

\begin{tabular}{|c|c|c|}
\hline INCPL & CPL & IRR \\
\hline $\operatorname{lia}^{4}$ & $\operatorname{liá}^{4}$ & $\operatorname{lia}^{42}$ \\
\hline $\operatorname{lia}^{3}$ & liá? ${ }^{1}$ & $\operatorname{lia}^{3}$ \\
\hline $\mathrm{lia}^{4}$ & lián ${ }^{3}$ & liá$^{4}$ \\
\hline lia? $?^{42}$ & $\mathrm{lia?}^{2}$ & $\mathrm{lia}^{2}$ \\
\hline
\end{tabular}

b. AN 'push animate'

INFL STEMS

\begin{tabular}{|c|c|c|c|}
\hline & PRS & PRF & FUT \\
\hline $1 \mathrm{SG}>\mathrm{AN}$ & $\operatorname{lia} P^{32}-a^{4}$ & $m a^{3}-$ liá$^{2}{ }^{2}-a^{4}$ & $\mathrm{Pi}^{2}-1 \mathrm{liaP^{1 }}{ }^{1} \mathrm{a}^{4}$ \\
\hline $2 \mathrm{SG}>\mathrm{AN}$ & $l i a P^{4}-u^{3}$ & $m a^{3}-l i a a^{42}-u^{3}$ & $2 i^{2}-l i a ?^{4}-u^{3}$ \\
\hline $3 \mathrm{SG}>\mathrm{AN}$ & $\operatorname{lia}\langle y\rangle ?^{32}$ & $m a^{3}-1$ liá $\langle y\rangle ?^{2}$ & Pí $^{4}-1$ liá$\langle y\rangle ?^{2}$ \\
\hline 1PL>AN & $\operatorname{lia} ?^{32}-a^{2}$ & $m a^{3}-1 i a a^{42}-a^{2}$ & $2 i^{2}-1 i a P^{42}-a^{2}$ \\
\hline
\end{tabular}

\begin{tabular}{|c|c|c|}
\hline INCPL & CPL & IRR \\
\hline $\mathrm{lia}^{32}$ & liá$^{2}$ & lia? ${ }^{1}$ \\
\hline $\operatorname{lia}^{4}$ & $\operatorname{lia}^{42}$ & $\operatorname{lia}^{4}$ \\
\hline $\operatorname{lia}^{32}$ & $\operatorname{liá}^{2}$ & liá? ${ }^{2}$ \\
\hline $\operatorname{lia}^{32}$ & $\operatorname{lia}^{42}$ & $\operatorname{lia}^{42}$ \\
\hline
\end{tabular}


The inanimate paradigm of the verb in (19) belongs to the invariant class and has tone $/ 3$ / for all cells. In contrast, its animate paradigm belongs to Class $g$ for the marking of 3rd person but to Class 20 for the marking of other persons, we can represent this as $\{g / 20\}$. The verb in (20) is $\{g / 7\}$ for the inanimate and $\{l / 11\}$ for the animate. The multiple permutations give rise to a system with many inflectional possibilities. For the values of such classes see the Appendix. The 67 paired verbs in the sample of this first pattern display 41 such combinations, which are given in Table 9. The combinations pertaining to verbs (19) and (20) are highlighted in shading.

\begin{tabular}{|c|c|c|c|c|c|c|c|c|c|}
\hline \multirow[b]{2}{*}{ \# } & \multicolumn{2}{|c|}{ INAN } & \multicolumn{2}{|c|}{ AN } & & \multicolumn{2}{|c|}{ INAN } & \multirow{2}{*}{\multicolumn{2}{|c|}{$\begin{array}{l}\mathrm{AN} \\
1 \mathrm{SG} / 2 / 1 \mathrm{PL}\end{array}$}} \\
\hline & 3 & $1 \mathrm{SG} / 2 / 1 \mathrm{PL}$ & 3 & $1 \mathrm{SG} / 2 / 1 \mathrm{PL}$ & $\#$ & 3 & $1 \mathrm{SG} / 2 / 1 \mathrm{PL}$ & & \\
\hline 1 & $b$ & 42 & 1321 & 68 & 1 & $q$ & - & /'4/ & 8 \\
\hline 1 & $g$ & 7 & $13 /$ & 5 & 3 & $q$ & _ & /'4/ & /'4/ \\
\hline 1 & $g$ & 7 & $14 /$ & 6 & 1 & $q$ & $\ldots$ & $g$ & 7 \\
\hline 2 & $g$ & 7 & $l$ & 5 & 1 & 121 & $\ldots$ & $/ 1 /$ & 8 \\
\hline 4 & $g$ & 7 & $l$ & 11 & 2 & $/ 2 /$ & _ & $14 /$ & 6 \\
\hline 3 & $g$ & 7 & $l$ & 14 & 1 & $/ 2 /$ & $\ldots$ & I'4/ & I'4/ \\
\hline 1 & $g$ & 7 & $l$ & 24 & 1 & /'2/ & $\ldots$ & $l$ & $l$ \\
\hline 3 & $g$ & 7 & $q$ & 11 & 4 & $13 /$ & _ & l'4l & /'4/ \\
\hline 1 & $g$ & 37 & $l$ & 5 & 1 & $13 /$ & $\ldots$ & $g$ & 20 \\
\hline 2 & $k$ & 16 & $132 /$ & 22 & 3 & $13 /$ & 22 & $14 /$ & 6 \\
\hline 1 & $k$ & 16 & $132 /$ & 68 & 1 & $/ 3 /$ & 27 & /'4/ & /'4/ \\
\hline 1 & $k$ & 17 & $132 /$ & 22 & 1 & $13 /$ & 63 & $l$ & 63 \\
\hline 1 & $l$ & 10 & $13 /$ & 18 & 1 & $/ 3 /$ & $\ldots$ & 141 & 6 \\
\hline 1 & $l$ & 10 & /'4/ & 8 & 1 & 1321 & 31 & $13 /$ & 18 \\
\hline 3 & $l$ & 19 & 131 & 5 & 1 & 141 & 6 & $13 /$ & 6 \\
\hline 2 & $l$ & 32 & $q$ & 25 & 1 & /'4/ & $\ldots$ & /'II & 8 \\
\hline 2 & $o$ & 16 & $q$ & 13 & 5 & /'4/ & I'4/ & $13 /$ & 5 \\
\hline 1 & $o$ & 20 & $q$ & 13 & 1 & /'4/ & 13 & $13 /$ & 5 \\
\hline 1 & $q$ & $\ldots$ & I'2/ & $/ 2 /$ & 1 & I'4/ & 22 & $l$ & 21 \\
\hline 1 & $q$ & $\ldots$ & 141 & 66 & 2 & I'4/ & 26 & 131 & 22 \\
\hline & & & & & 1 & I'4/ & 65 & $/ 2 /$ & 13 \\
\hline Total & & & & & 67 & & & & \\
\hline
\end{tabular}

Table 9. Prosodic inflection in the 67 paired verbs of the first pattern.

The second pattern is instantiated by 42 paired verbs. In this pattern, the forms for the 3rd person inanimate and animate are prosodically identical, while the forms for the other persons remain contrastive. An example is given in (21). 
(21) $P \imath^{4} c t^{1} a^{2}(\operatorname{tr})$ 'knock over'

a. INAN 'knock something over'

INFL STEMS

\begin{tabular}{|c|c|c|c|c|c|c|}
\hline & PRS & PRF & FUT & INCPL & CPL & IRR \\
\hline $1 \mathrm{SG}>\mathrm{INAN}$ & $c^{\prime} \dot{\prime}\langle y\rangle ?^{4}$ & $m a^{3}-c^{\prime}\langle y\rangle ?^{4}$ & $P^{1} 1^{4}-c^{\prime}\langle y\rangle P^{4}$ & $c^{\prime} \mathrm{P}^{4}$ & CÁ? $^{4}$ & CÍ $^{4}{ }^{4}$ \\
\hline $2 \mathrm{SG}>\mathrm{INAN}$ & $c \dot{c}\langle y\rangle ?^{32}$ & $m a^{3}-c^{\prime}\langle y\rangle ?^{2}$ & $P^{\prime} 1^{4}-c \dot{z}\langle y\rangle ?^{1}$ & $\operatorname{cit}^{32}$ & Cí? $^{2}$ & $\operatorname{cis}^{1}$ \\
\hline $3 \mathrm{SG}>\mathrm{INAN}$ & $\operatorname{cit}^{32}$ & $m a^{3}-c_{1}^{\prime} ?^{2}$ & $P_{1}^{4}-c t^{\prime} P^{2}$ & $\operatorname{cit}^{32}$ & CÁ? $^{2}$ & Cí? ${ }^{2}$ \\
\hline 1PL $>$ INAN & $\mathrm{cit}^{32}-\mathrm{a}^{2}$ & $m a^{3}-c \dot{i} ?^{1}-a^{2}$ & $P^{4} i^{4}-c \dot{i} P^{1}-a^{2}$ & $\operatorname{cit}^{32}$ & cì? ${ }^{1}$ & cí? ${ }^{1}$ \\
\hline
\end{tabular}

b. AN 'knock animate over'

INFL STEMS

\begin{tabular}{|c|c|c|c|c|c|c|}
\hline & PRS & PRF & FUT & INCPL & CPL & IRR \\
\hline $1 \mathrm{SG}>\mathrm{AN}$ & $\operatorname{cip}^{42}-a^{4}$ & $m a^{3}-c i^{42}-a^{4}$ & $P^{\prime 4}-c \dot{1} P^{42}-a^{4}$ & $\operatorname{cip}^{42}$ & $\operatorname{cip}^{42}$ & $\operatorname{cit}^{42}$ \\
\hline $2 \mathrm{SG}>\mathrm{AN}$ & $\operatorname{cip}^{42}-u^{3}$ & $\mathrm{ma}^{3}-\mathrm{cip}^{42}-\mathrm{u}^{3}$ & $P^{\prime 4}-c \dot{i} P^{42}-u^{3}$ & $\mathrm{cip}^{42}$ & $\mathrm{cip}^{42}$ & $\operatorname{cip}^{42}$ \\
\hline $3 \mathrm{SG}>\mathrm{AN}$ & $\operatorname{cip}^{32}$ & $m a^{3}-c^{\prime} t^{2}$ & $P_{1}^{4}-c_{1}^{\prime} P^{2}$ & $\operatorname{cit}^{32}$ & $c_{i}^{\prime} ?^{2}$ & ct́ $^{\prime}{ }^{2}$ \\
\hline 1PL>AN & $\operatorname{cip}^{32}-a^{2}$ & $m a^{3}-c i P^{42}-a^{2}$ & $P^{\prime 4}-\mathrm{cti}^{42}-\mathrm{a}^{2}$ & $\operatorname{cip}^{32}$ & $\operatorname{cit}^{42}$ & $\operatorname{cit}^{42}$ \\
\hline
\end{tabular}

The verb in (21) belongs to Class $\{l, 10\}$ when inanimate and $\{l, 5\}$ when animate. The 42 verbs display the 17 different inflectional possibilities given in Table 10. One of such classes has up to 16 members.

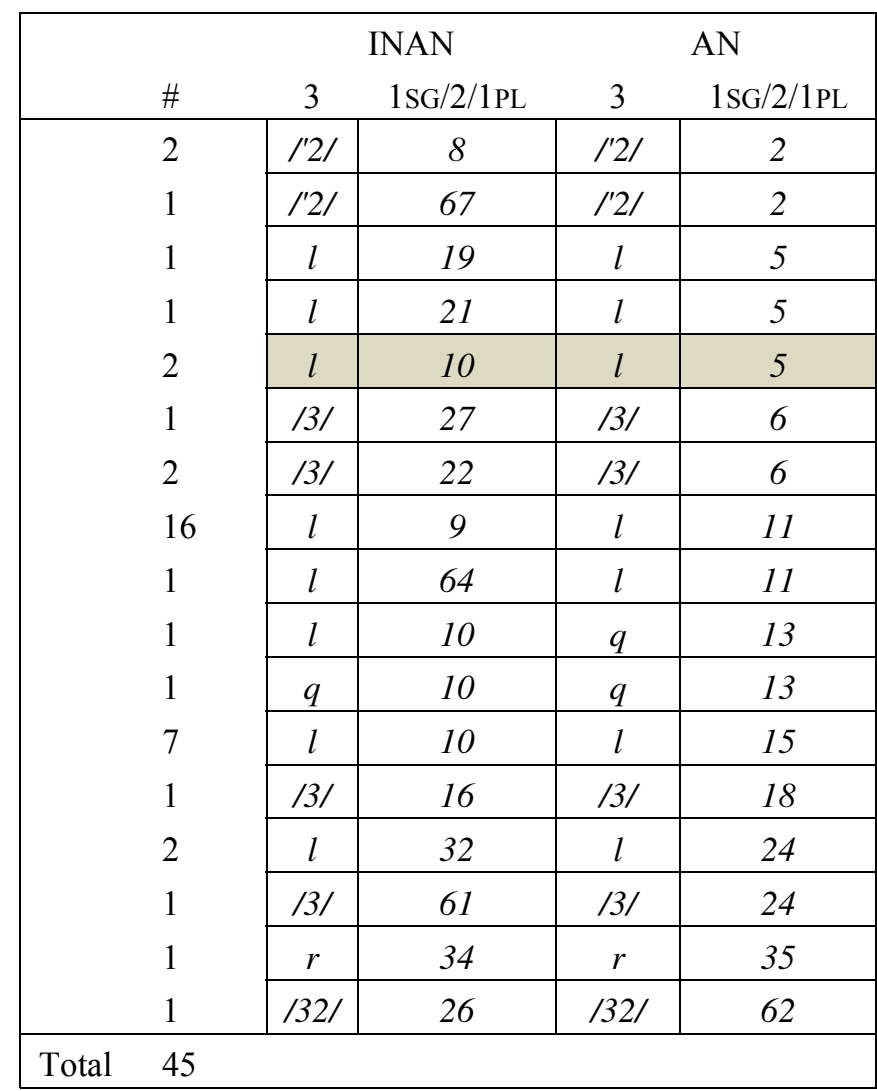

Table 10. Prosodic inflection in the 42 paired verbs of the second pattern.

The remaining 66 paired verbs in the sample do not change in prosodic inflection when they are inflected as animate or inanimate. Relevant examples are given in (22) and (23). 
(22) ' $P i^{4}$ gwii ${ }^{4}$ (intr) 'get cold' $\{/ 4 /, 6\}$

a. INAN 'for something to get cold'

INFL STEMS

\begin{tabular}{|c|c|c|c|}
\hline & PRS & PRF & FUT \\
\hline SGINAN & gwii? ${ }^{4}$ & $m^{3}$-gwii? ${ }^{4}$ & $P 1^{4}$-gwii? ${ }^{4}$ \\
\hline
\end{tabular}

\begin{tabular}{|l|l|l|}
\multicolumn{1}{l}{ INCPL } & \multicolumn{1}{l}{ CPL } & \multicolumn{1}{l}{ IRR } \\
\hline gwii? $^{4}$ & gwii? $^{4}$ & gwii? $^{4}$ \\
\hline
\end{tabular}

b. AN 'for animate to get cold'

INFL STEMS

\begin{tabular}{|c|c|c|c|c|c|c|}
\hline & PRS & PRF & FUT & INCPL & CPL & IRR \\
\hline $1 \mathrm{SG}$ & gwii? ${ }^{42}-a^{2}$ & $\mathrm{ma}^{3}$-gwii? ${ }^{42}-a^{2}$ & $P^{14} 1^{4}$ gwii? $P^{42}-a^{2}$ & gwii? $^{42}$ & gwii? $^{42}$ & gwii? $^{42}$ \\
\hline $2 \mathrm{SG}$ & gwii? ${ }^{4}-u^{3}$ & $m^{3}-g w i i ?^{4}-u^{3}$ & $P^{1^{4}}-g w i i^{4}-u^{3}$ & gwii? $^{4}$ & gwii? $^{4}$ & gwii? $^{4}$ \\
\hline 3SG.AN & gwii? ${ }^{4}-y$ & ma $^{3}$-gwii? ${ }^{4}-y$ & $P^{4} 1^{4}-g w i i ?^{4}-y$ & gwii? $^{4}$ & gwii? $^{4}$ & gwii? $^{4}$ \\
\hline 1PL.INCL & gwii? ${ }^{42}-a^{2}$ & $\mathrm{ma}^{3}-$ gwii? ${ }^{42}-\mathrm{a}^{2}$ & $\mathrm{Pi}^{4}-\mathrm{gwiiP}{ }^{42}-\mathrm{a}^{2}$ & gwii? $^{42}$ & gwii? $^{42}$ & gwii? $^{42}$ \\
\hline
\end{tabular}

(23) $P i^{2} g w a P^{42} a^{2}$ (tr) 'change' $\{l, 5\}$

a. INAN 'change something'

INFL STEMS

\begin{tabular}{|c|c|c|c|}
\hline & PRS & PRF & FUT \\
\hline $1 \mathrm{SG} \gg \mathrm{INAN}$ & gwa<y $>?^{42}$ & $m a^{3}-g w a<y>?^{42}$ & $P^{2} i^{2}$ gwa<y> $?^{42}$ \\
\hline $2 \mathrm{SG} \gg \mathrm{INAN}$ & gwa $\langle y\rangle ?^{42}$ & $m a^{3}-$ gwa $(y) ?^{42}$ & $\mathrm{Pi}^{2}-$ gwa<y> $?^{42}$ \\
\hline 3SG $\gg$ INAN & gwa? $^{32}$ & $\mathrm{ma}^{3}$-gwá ${ }^{2}$ & Pí $^{4}$-gwá? ${ }^{2}$ \\
\hline $1 P L \gg I N A N$ & $g w a ?^{32}-a^{2}$ & $m a^{3}-g w a ?^{42}-a^{2}$ & $\mathrm{Pi}^{2}-g w a P^{42}-a^{2}$ \\
\hline
\end{tabular}

b. AN 'change entity'

\begin{tabular}{|c|c|c|c|}
\hline & PRS & PRF & FUT \\
\hline $1 \mathrm{SG}>\mathrm{AN}$ & $g w a<y>?^{42}-a^{2}$ & $m a^{3}-g w a<y>P^{42}-a^{2}$ & $2 i^{2}-g w a<y>?^{42}-a^{2}$ \\
\hline $2 \mathrm{SG}>\mathrm{AN}$ & gwa $<y>?^{42}-u^{3}$ & $m a^{3}-g w a<y>?^{42}-u^{3}$ & $P^{2}{ }^{2}-g w a<y>P^{42}-u^{3}$ \\
\hline $3 \mathrm{SG}>\mathrm{AN}$ & gwa<y>? $3^{32}$ & $m a^{3}-$ gwá $\langle y\rangle ?^{2}$ & $P^{\prime 4}$-gwá<y>? \\
\hline $1 \mathrm{PL}>\mathrm{AN}$ & $\operatorname{gwaP}^{32}-\mathrm{a}^{2}$ & $m a^{3}-g w a ?^{42}-a^{2}$ & $\mathrm{Pi}^{2}-g w a \mathrm{P}^{42}-\mathrm{a}^{2}$ \\
\hline
\end{tabular}

\begin{tabular}{|l|l|l|}
\multicolumn{1}{|l}{ INCPL } & CPL & \multicolumn{1}{l}{ IRR } \\
\hline gwa? $^{42}$ & gwa? $^{42}$ & gwa? $^{42}$ \\
\hline gwa? $^{42}$ & gwa? $^{42}$ & gwa? $^{42}$ \\
\hline gwa? $^{32}$ & gwá? $^{2}$ & gwá? $^{2}$ \\
\hline gwa? $^{32}$ & gwa? $^{42}$ & gwa? $^{42}$ \\
\hline
\end{tabular}

INFL STEMS

\begin{tabular}{|c|c|c|}
\hline & CPL & IRR \\
\hline gwa? $^{42}$ & gwa? $^{42}$ & gwa? $^{42}$ \\
\hline gwa? $^{42}$ & gwa? $^{42}$ & gwa $^{42}$ \\
\hline $\operatorname{gwaP}^{32}$ & & \\
\hline $\operatorname{gwa}^{32}$ & gwa $^{42}$ & gwa? $^{42}$ \\
\hline
\end{tabular}

In this section, we have seen that at least two thirds of the paired verbs of the sample inflect as animate and inanimate in rather unpredictable ways. Like with non-paired verbs, if prosody does not work as an optimal way to inform about the animacy of a verb, it makes sense -at least from a morphosyntactic point of view- that other parts of the system do the job. In the following section, I show that the suffix sets of the major suffix classes (i.e., Classes 1,2 and 3) have a clear morphosyntactic function in the realization of animacy agreement with pairedverbs, which are the ones that have more need of it for inflectional purposes.

Finally, alternative views of paired verbs are possible. For example, one could claim that they represent two independent lexemes related semantically through derivation. Under such a view the morphological irregularities they display would be accounted for as being in effect typical of derivation, while verbs in (22) and (23) would have to be seen as 'ambianimate' by undergoing some sort of zero conversion from animate to inanimate and vice versa. But if the verbs were to be seen as related through derivation, the fact that the suffixes display a clearer mapping from function to form precisely with them would still want an explanation. This is why the treatment of paired verbs as inflectional has advantages for the analysis of the suffixes. Nevertheless, appealing to derivation as an argument to account for the morphological irregularity we observe in Tables 9 and 10 would be weak in the light of 
other tables such as Table 4 that show that prosodic inflection in Chinantec is rich in irregularities.

\subsubsection{Paired verbs and the suffix classes.}

In this section, I show the distribution of the suffix classes used in the inflection of 175 paired verbs. For this purpose consider the figures in Table 11, (shading highlights where marking preferences lie).

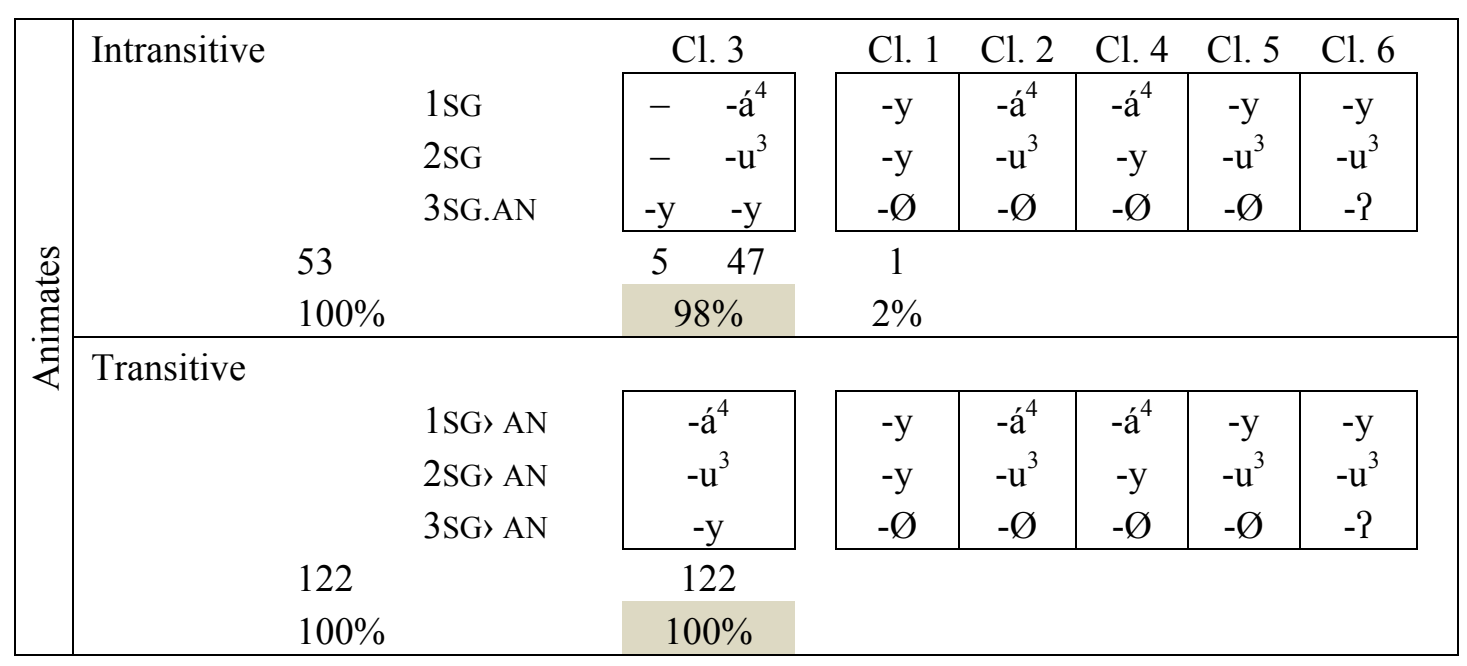

\begin{tabular}{|c|c|c|c|c|c|c|c|c|c|}
\hline \multirow{12}{*}{ 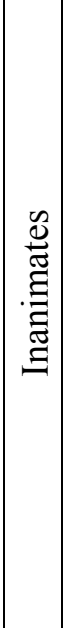 } & \multirow{4}{*}{\multicolumn{2}{|c|}{ Intransitive }} & & Cl. 3 & Cl. 1 & Cl. 2 & Cl. 4 & Cl. 5 & Cl. 6 \\
\hline & & & $1 \mathrm{SG}$ & - & - & - & - & - & - \\
\hline & & & $2 \mathrm{SG}$ & - & - & - & - & - & - \\
\hline & & & 3SG.INAN & $-\mathrm{y}$ & \multicolumn{4}{|c|}{$-\varnothing$} & $-?$ \\
\hline & & 53 & & 2 & \multicolumn{4}{|c|}{51} & \\
\hline & & $100 \%$ & & $2 \%$ & \multicolumn{4}{|c|}{$96 \%$} & \\
\hline & \multicolumn{9}{|l|}{ Transitive } \\
\hline & & & 1SG $>$ INAN & $-a^{4}$ & $-\mathrm{y}$ & $-a^{4}$ & $-a^{4}$ & $-y$ & $-y$ \\
\hline & & & $2 \mathrm{SG}>\mathrm{INAN}$ & $-u^{3}$ & $-y$ & $-u^{3}$ & $-y$ & $-u^{3}$ & $-u^{3}$ \\
\hline & & & $3 \mathrm{SG}>\mathrm{INAN}$ & $-y$ & $-\varnothing$ & $-\varnothing$ & $-\varnothing$ & $-\varnothing$ & $-?$ \\
\hline & & 122 & & 1 & 79 & 37 & 2 & 3 & \\
\hline & & $100 \%$ & & $1 \%$ & $65 \%$ & $30 \%$ & $1.5 \%$ & $2.5 \%$ & \\
\hline
\end{tabular}

Table 11. The 175 paired verbs of the sample.

In Table 11, we can see that Class 3 is aligned with animacy. We have seen a similar tendency in animate non-paired verbs in Table 5, but there the distribution was more spread out in the other classes. The same can be said at least for the use of a bare stem, which indisputably identifies the presence of an inanimate argument. For transitive inanimate verbs, the situation is very different from non-paired verbs. With the latter, the distribution of Classes 1 and 3 were even, but with paired verbs, the preference is for Class 1 . There are still a sizeable number of verbs in Class 2, which would need explaining, because their presence is comparable to the $11 \%$ we find in equivalent non-paired verbs. The figures in Table 11 reveal clear preference for the selection of a particular set of suffixes according to the animacy of the 
verb. I take such preferences to reveal the application of the morphosyntactic mapping I develop in the next section.

\section{The suffix classes and the morphosyntax of agreement.}

\subsection{Revisiting the morphosyntax of animacy agreement.}

One could say that the major marking tendencies we observe with paired verbs responds to a morphosyntactic mapping from function to form. The mapping could be said to have the form in (24).

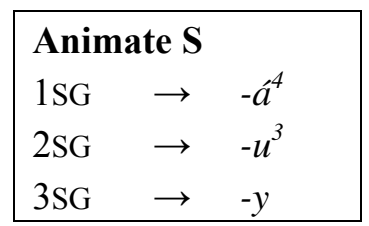

\begin{tabular}{|lll|}
\hline \multicolumn{3}{|l|}{$\mathrm{A}>$ Animate } \\
$1 \mathrm{SG}$ & $\rightarrow$ & $-\hat{a}^{4}$ \\
$2 \mathrm{SG}$ & $\rightarrow$ & $-u^{3}$ \\
$3 \mathrm{SG}$ & $\rightarrow$ & $-y$ \\
\hline
\end{tabular}

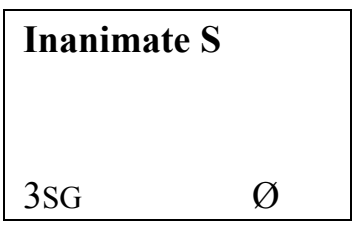

\begin{tabular}{|c|c|c|}
\hline \multicolumn{3}{|c|}{ A > Inanimate $\mathbf{O}$} \\
\hline $1 \mathrm{SG}$ & $\rightarrow$ & $-y$ \\
\hline $2 \mathrm{SG}$ & $\rightarrow$ & $-y$ \\
\hline $3 \mathrm{SG}$ & $\rightarrow$ & \\
\hline
\end{tabular}

The mapping in (24) includes information about subject (S/A) and information about animacy of S/O. Because of this, it could ideally be divided up further. One possibility is to posit that the person-number paradigm bears a split between the cells involving a subject of $1 \mathrm{SG}$ and $2 \mathrm{SG}$, on the one side, and those involving a $3 \mathrm{SG}$, on the other. Let us deal with $3 \mathrm{SG}$ first.

On the one hand, an intransitive inanimate verb can only be inflected in $3 \mathrm{SG}$, and in paired verbs this information is encoded by a bare stem by default. On the other hand, transitive verbs can have a subject in all persons, but their object is inanimate. To encode a transitive situation involving a $3 \mathrm{SG}$ acting on an inanimate object $(>)$, a bare stem is also used. One possible way to interpret these similarities in form (i.e. use of a bare stem for both situations) is to take them to reflect similarities in function. Accordingly, the use of a bare stem could be taken to signal the inanimate gender of an absolutive argument $S / O$, as in (25), illustrated by the forms in (26), please note that the inflected stem also carries information about person-number of the subject.

(25) INAN.S/INAN.O $\rightarrow$ bare stem (-Ø)
a. 3SG.INAN
Pí ${ }^{4}-h \underline{e}^{4}$
FUT-get.close.IRR.3[3SG.INAN]
'It'll get closer.'
a. 3SG $>$ INAN
Pí ${ }^{4}-1 i a ́{ }^{4}$
FUT-push.IRR.3[3SG>INAN]
'He'll push it.' 
Similarly, $-y$ is used to index either an animate $\mathrm{S}$ or an animate $\mathrm{O}$, so it could be taken to signal agreement with the animacy of the absolutive argument $\mathrm{S} / \mathrm{O}$, regardless of whether the $\mathrm{O}$ is $3 \mathrm{SG}$ like in (27a) or any other person, like in (27b) or (27c). So the mapping could be the one in (28).
a. $3 \mathrm{SG}>\mathbf{A N}$
Pí ${ }^{4}-1$ iá $\left\langle\mathbf{y}>?^{2}\right.$
FUT-push.AN.IRR.3<3SG $>$ AN $>$
'He'll push him/her.'

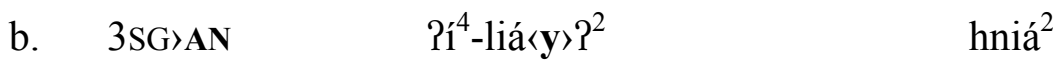
FUT-push.AN.IRR.3 $<3 \mathrm{SG}>\mathrm{AN}>\quad 1 \mathrm{SG}$
'He'll push me.'

c. $3 \mathrm{SG}>\mathbf{A N}$
$\operatorname{diá}^{4} \mathrm{za}^{3} \quad \mathrm{ni}^{3} \quad \mathrm{ka}^{4}-\mathrm{daP}^{1}-$ hoó$^{1}-\mathbf{y} \quad \mathrm{niu}^{3}$
PL person FOC PST-3PL-see.AN.CPL.3-3SG>AN 2SG
'Those people saw you.' (R: 30$)$

\section{(28) AN.S/AN.O}

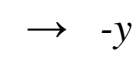

The mappings in (25) and (28) are only used in the context of a 3rd person subject, so when they are used, they indirectly convey information of subject as well.

We still need to account for the configurations involving a subject of $1 \mathrm{SG}$ and $2 \mathrm{SG}$. In this regard, the majority (65\%) of the transitive inanimate verbs in the pairs belong to Class 1 . This means that they select the suffix $-y$ as exponent for both $1 \mathrm{SG}$ and $2 \mathrm{SG}$. It is more difficult to make sense of this in a coherent way. Probably the easiest way out is to interpret that this $-y$ has a different function from the $-y$ in (29) while being coincidentally homophonous. ${ }^{18}$ In this light, one could propose the mappings in (30).

$\begin{array}{llll}\text { (29) } & \text { AN.S/AN.O } & \rightarrow & -y_{1} \\ \text { (30) } & 1 \mathrm{SG}>\text { INAN/2SG }>\text { INAN } & \rightarrow & -y_{2}\end{array}$

\footnotetext{
${ }^{18}$ A second possibility is to think that $-y_{2}$ is a leftover of a once productive direct/inverse system where it indicated direct in configurations such as $1>3$.INAN or $2>3$.INAN. While other Chinantecan languages are analyzed as having a fully-fledged morphological inverse, for example in Sochiapam Chinantec (Foris 2000), there is little or no evidence for an inverse marking in Lealao Chinantec, and the fact that $-y_{2}$ is not used for situations such as $1>3$.AN or $2>3$.AN makes it unlikely that this solution is appropriate. A third possibility would involve regarding the $-y_{2}$ in such forms as being the same as $-y_{1}$. For such an option to work, one would need to resort to a convoluted solution by positing two affixal slots in the inflected forms for 1SG and 2SG subject in inanimate verbs. The first slot would be used by a bare stem in a mapping similar to (25) indicating inanimate $\mathrm{O}$ (which in context is interpreted as of $3 \mathrm{SG}$ ), the other slot corresponding to $-y$ indicating animate subject (which in context is interpreted as 1SG or 2SG subject). Such structure is represented in the glossing of the form in (i).
}

(i) $1 \mathrm{SG}>\mathbf{I N A N} \quad \mathrm{ii}^{2}-\operatorname{lia}\langle\mathrm{y}\rangle \mathrm{P}^{42}$

FUT-push.INAN.IRR.1SG[INAN (3OBJ)] AN(1SUB)>

'I'll push it.' 
The situations in (25), (29) and (30) are specific. For all other possibilities, namely when $1 \mathrm{SG}$ or $2 \mathrm{SG}$ function as S or when they function as A of verbs with an animate object, a default or elsewhere case applies. As both situations are equally encoded by $-\hat{a}^{4}$ and $-u^{3}$, respectively, it seems that what is important now is the marking of subject (S/A), as in (31).

$$
\text { (31) } \begin{array}{rll}
1 \mathrm{SG} & \rightarrow-a^{4} \\
2 \mathrm{SG} & \rightarrow-u^{3}
\end{array}
$$

A summary of the proposal is given in (32):

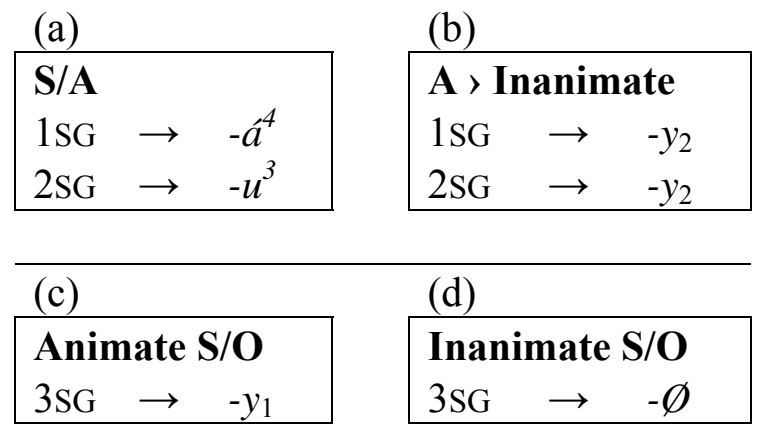

When the subject is of $1 \mathrm{SG}$ and $2 \mathrm{SG}$ the situation in (a) serves as a default in the sense of the elsewhere case, while (b) applies to a smaller subclass within (a). This allows for the marking of (a) to also apply to situations that have an inanimate object as indeed happens with the verbs that are characterized as Class 2 in Table 11. Such verbs amount to 37, but 30 of them are verbs of the type in (22-23), which do not use prosodic inflection to encode animacy. Another example of this type of verb is given in (33), with an indication of the suffixes the verb requires.

\begin{tabular}{|c|c|c|c|}
\hline \multirow[b]{2}{*}{$1 \mathrm{SG}$} & PRS & PRF & FUT \\
\hline & $\mathrm{ti}_{\underline{i}^{42}}-\mathrm{a}^{2}$ & $m a^{3}-t^{3} \underline{t}^{3}-a^{4}$ & $2 i^{4}-t i^{4}-a^{4}$ \\
\hline $2 \mathrm{SG}$ & $t \dot{t}^{4}-u^{3}$ & $m a^{3}-t^{3} \underline{t}^{3}-u^{3}$ & $3 i^{4}-t^{4} \underline{t}^{4}-u^{3}$ \\
\hline $3 \mathrm{SG}>\mathrm{AN}$ & $t \underline{t}^{4}-y$ & $m a^{3}-t^{3}-y$ & $2 i^{4}-t^{4}-y$ \\
\hline $3 \mathrm{SG}>\mathrm{INAN}$ & $t \underline{i}^{4}$ & $\mathrm{ma}^{3}-\mathrm{tit}^{3}$ & $3 i^{4}-t^{4} \underline{t}^{4}$ \\
\hline $1 P L$ & $\mathrm{ti}^{42}-\mathrm{a}^{2}$ & $m a^{3}-t^{3} \underline{t}^{3}-a^{2}$ & $2 i^{4}-t t^{4}-a^{2}$ \\
\hline
\end{tabular}

$$
i^{4} t_{\underline{t}}^{4} a^{2}(\operatorname{tr}, \text { an) 'receive' }\{g, 69\}
$$

SUFF.
\begin{tabular}{|l|} 
CL. 2 \\
\hline$-a^{4}$ \\
\hline$-u^{3}$ \\
\hline$-y$ \\
\hline$-\emptyset$ \\
\hline$-a^{2}$ \\
\hline
\end{tabular}

Verbs like (33) abide by the default in (a) and are thus not perceived as members of (b). This has two very interesting consequences for the system: (i) while a great number of inanimate transitive verbs are inflected attending to (b), it makes (b) become an inflectional class whose membership needs to be dictated by the lexicon. Even if we defined the exceptions to (b) as being of the type of verbs in (33), there are still 8 verbs of the other patterns in Tables 9 and 10 that would escape the generalization; (ii) because (a) is a default, it strongly suggests that 
the marking of agreement with subject (S/A) is more important to the system than marking animacy, at least when a 1 st and a 2 nd person are involved. We can see the impact of the preference of the agreement system based on subject in verbs of the type in (33) in that a form such as $P i^{A} t_{\underline{t}}^{A} a^{4}\{1 \mathrm{SG} . \mathrm{FUT}\}$ means both 'I'll receive something' and 'I'll receive someone', or rather, just 'I receive (an object)'.

Finally, at least for the context of a 3rd person subject, the mapping still works for paired verbs attending to the animacy of $\mathrm{S} / \mathrm{O}$, but when we compare this with non-paired verbs, the form-function correspondence in (c) and (d) leaks. All these facts reveal that the morphosyntax of animacy agreement in Lealao Chinantec is less prominent than the morphosyntax of subject agreement. This is something I discuss further in the next section.

\subsection{Revisiting the morphosyntax of subject agreement.}

In the previous section, we have seen that the morphosyntactic mapping in (32) which accounts for most instances of animacy agreement in paired verbs already implies a situation where $1 \mathrm{SG}$ and $2 \mathrm{SG}$ are subject. If we study the encoding of these person-number values in the sample as a whole, we find four encoding strategies: (a) using the suffixes $-\hat{a}^{4}$ and $-u^{3}$ for either value; (b) using the suffix $-y$ for both values; or the heteroclite options in (c) or (d), which result as a combination of (a) and (b). The relevant figures are given in Table 12, based on all 848 entries in the sample that can inflect for a 1st or 2 nd person subject.

\begin{tabular}{|c|c|c|c|c|c|c|}
\hline \multicolumn{7}{|l|}{$1 \mathrm{SG}, 2 \mathrm{sG}$} \\
\hline \multirow{4}{*}{$\begin{array}{ll}\text { a. } & -a^{4},-u^{3} \\
\text { b. } & -y,-y \\
\text { c. } & -a^{4},-y \\
\text { d. } & -y,-u^{3}\end{array}$} & - & 199 & 176 & 234 & 609 & $72 \%$ \\
\hline & - & 24 & 186 & 0 & 210 & $25 \%$ \\
\hline & - & 0 & 2 & 7 & 9 & $1 \%$ \\
\hline & - & 9 & 11 & 0 & 20 & $2 \%$ \\
\hline Total & - & 232 & 375 & 241 & 848 & $100 \%$ \\
\hline
\end{tabular}

Table 12. The encoding $1 \mathrm{SG}$ and $2 \mathrm{SG}$ in 848 entries.

The figures in Table 12 reveal that strategy (a) serves as a default, both in its sense of the elsewhere case and the most frequent option, suggesting that the suffixes $-a^{4}$ and $-u^{3}$ function as default indexes of subject of $1 \mathrm{SG}$ and $2 \mathrm{SG}$ without any significant correlation with animacy. Strategy (b), is the second most favored option, it constitutes a lexically defined class of verbs with a great majority of inanimate transitives.

All this points to the existence of an agreement system in Lealao Chinantec that is hybrid between encoding information about subject agreement and about animacy agreement. Information about animacy is scattered. In the mapping in (32) it was mainly at work in the configurations in (b) and (c). But outside paired verbs, the association of $-y$ is no longer restricted to animacy. To show this, consider Table 13, where I give the distribution for the three coding strategies of a 3 SG subject in the whole sample: (a) is the suffix $-y$; (b) is by using a stem with no exponent; and (c) is by means of the suffix -?. 


\begin{tabular}{|c|c|c|c|c|c|c|}
\hline \multicolumn{7}{|l|}{$3 \mathrm{SG}$} \\
\hline \multirow{3}{*}{$\begin{array}{ll}\text { a. } & -y \\
\text { b. } & -\varnothing\end{array}$} & S.INAN & S.AN & A $\gg$ INAN & $A>A N$ & \multicolumn{2}{|c|}{ Total } \\
\hline & 67 & 211 & 112 & 234 & 624 & $53.6 \%$ \\
\hline & 212 & 51 & 267 & 9 & 539 & $46.2 \%$ \\
\hline c. $-?$ & 0 & 3 & 0 & 0 & 3 & $0.2 \%$ \\
\hline Total & 279 & 265 & 379 & 243 & 1166 & $100 \%$ \\
\hline
\end{tabular}

Table 13. The encoding 3SG in the 1166 entries of the sample.

While the workload of strategy (c) is utterly insignificant for the syntax, strategies (a) and (b) have comparable frequencies. In other words, they instantiate two inflectional classes which have an equal amount of labor regarding the encoding of $3 \mathrm{rd}$ person subject. We have seen in the mapping in (32) that at least for paired verbs, the reference to a 3rd person subject is indirect, the emphasis lying on an animacy distinction of the S/O. However, when the whole system is taken into account, the function of $-y$ or $-\varnothing$ can no longer be said to be linked to animacy. This is particularly relevant for $-y$ because the figures in Table 13 indicate that there is some expectation for a bare stem NOT to be used to realize 3SG subject with an animate $\mathrm{O}$. As no similar expectation can be said of $-y$, it strongly suggests that $-y$ is a default exponent of a 3SG subject, regardless of animacy.

The favored strategy for the encoding of $1 \mathrm{SG}$ and $2 \mathrm{SG}$ together with the default strategy for the encoding of $3 \mathrm{SG}$ shows that Class 3 serves as a default mapping of subject, given in (34), while still being strongly associated to verbs with an animate $\mathrm{S} / \mathrm{O}$ argument.

$$
\begin{aligned}
& \mathrm{S} / \mathrm{A} \\
& \begin{array}{|lll|}
1 \mathrm{SG} & \rightarrow & -a^{4} \\
2 \mathrm{SG} & \rightarrow & -u^{3} \\
3 \mathrm{SG} & \rightarrow & -y \\
\hline
\end{array}
\end{aligned}
$$

Class 3 is also the largest class; the remainder of the verbal lexicon gathers in the rest of the classes in an uneven way. The membership to the suffix classes is still largely a lexical matter, and hence a treatment in inflectional classes is justified, but there are tendencies in such membership involving the animacy features of the S/O argument of the verb. The general distribution of the classes attending to animacy value is given in Table 14 for the 848 verbs in the samples which can inflect in all persons. Notice that Table 14 cannot give information about $\{$ S.INAN\}. For the distribution of this value the classes taken as whole paradigms are not informative, and only Table 13 should be informative. The zeros of 3SG could pertain to at least four classes, but as pointed out above, the 67 verbs that manifest $-y$ for $\{$ S.INAN $\}$ can only be understood as pertaining to Class 3 . 


\begin{tabular}{|c|c|c|c|c|c|c|c|c|c|c|c|c|}
\hline & & S.AN & O.INAN & O.AN & Total & S.AN & O.INAN & O.AN & Total & S.AN & O.INAN & O.AN \\
\hline Class 1 & $-y,-y,-\varnothing$ & 24 & 186 & 0 & 210 & $11.5 \%$ & $88.5 \%$ & - & $100 \%$ & $10.5 \%$ & $49.6 \%$ & - \\
\hline Class 2 & $-a^{4},-u^{3},-\varnothing$ & 10 & 65 & 2 & 77 & $13 \%$ & $84.5 \%$ & $2.5 \%$ & $100 \%$ & $4.3 \%$ & $17.4 \%$ & $0.8 \%$ \\
\hline Class 3 & $-a^{4},-u^{3},-y$ & 189 & 111 & 232 & 532 & $35.5 \%$ & $21 \%$ & $43.5 \%$ & $100 \%$ & $81.5 \%$ & $29.6 \%$ & $96.2 \%$ \\
\hline Class 4 & $-\hat{a}^{4},-y,-\varnothing$ & 0 & 2 & 7 & 9 & - & $22 \%$ & $78 \%$ & $100 \%$ & - & $5.2 \%$ & $3 \%$ \\
\hline Class 5 & $-y,-u^{3},-\varnothing$ & 6 & 11 & 0 & 17 & $35 \%$ & $65 \%$ & & $100 \%$ & $2.5 \%$ & $2.8 \%$ & - \\
\hline Class 6 & $-y,-u^{3},-?$ & 3 & 0 & 0 & 3 & $100 \%$ & - & - & $100 \%$ & $1.2 \%$ & $\ldots$ & - \\
\hline & Total & 232 & 375 & 241 & 848 & & & & & $100 \%$ & $100 \%$ & $100 \%$ \\
\hline
\end{tabular}

Table 14. The classes and animacy configurations

Being a default, Class 3 is found for all animacy values, but shows preferences for the animate value as most verbs with an $\{$ S.AN $\}$ argument and practically all with $\{$ O.AN $\}$ are members of this class. Most of the verbs of Class 1 have $\{$ O.INAN\}, but only half of the verbs with \{O.INAN\} are found in Class 1, the rest are distributed in other four classes.

The system we observe in Lealao Chinantec is remarkably similar in typological terms to the inflectional class systems found in better-known Indo-European languages where gender plays a major part in class membership, as discussed for example in Wurzel (1984), Corbett and Fraser (1993), Fraser and Corbett (1994), Aronoff (1994), among others. For example, Russian nouns are said in the literature to fall into four inflectional classes (see Corbett and Fraser 1993, Müller 2004, etc.), and the membership of such classes show strong correlations with gender. ${ }^{19}$ One class contains all masculine nouns, while a second one contains all neuter nouns. Masculine nouns are also found in a third class that instead is mostly populated by feminine nouns, which in turn are virtually the only type of nouns found in the fourth class. The case of Lealao Chinantec is very similar to this situation if one sees animacy as a type of gender. But perhaps, because verbs in Chinantec are often still talked about as being targets of animacy agreement rather than controllers, the typological simile would perhaps have to be made with agreeing adjectives organized in inflectional classes.

\section{Concluding remarks.}

In this paper, I have shown that verbs in Lealao Chinantec receive different sets of suffixes for the person-number values $1 \mathrm{SG}, 2 \mathrm{SG}$, and $3 \mathrm{SG}$ which have a puzzling distribution because whereas they are used to index agreement of subject, just like other suffixes for 1PL and 2PL which have no allomorphy, they also convey information about the animacy of the S/O argument of the verb. I have identified six inflectional classes involving the suffixes -four in Rupp \& Rupp's (1996) account- although three of them comprise the greater bulk of verbs in a sample of over 1,000 verbal entries.

Studying the distribution of these suffixes, I have concluded that they manifest a mixed system of agreement, combining a more canonical system based on subject agreement (S/A) which is default and another based on the animacy features of the S/O. The morphology involved in the main three classes responds to a morphosyntactic mapping that is operational in verbs with two animacy paradigms. But as there are important mismatches in the meaningto-form correspondences in the inflection of verbs with only one animacy value, the system

\footnotetext{
${ }^{19}$ These classes receive different number labels according to analysis and tradition, so I will only refer to them generically here.
} 
ceases to be functional and a treatment of the suffixal allomorphy in inflectional class terms is justified.

As it is widely accepted nowadays in grammaticalization theory that transparent morphosyntactic systems often develop into more morphologically opaque ones (Givón's (1971) aphorism that today's morphology is yesterday's syntax), it seems reasonable to think that the functional morphosyntactic mapping we observe at work in paired verbs was perhaps prior to the system, but evolved into another system where the link between function and form has been broken for a substantial set of the lexicon. In lack of diachronic evidence to support it, this trend of thought should remain at a speculation level. However, the mixed morphological system we observe synchronically can shed new lights on a typology of agreement, as developed in Corbett (2006), Evans (2003), Polinsky (2003), etc.

Lealao Chinantec is one of the many endangered indigenous languages of Mexico, and we can only hope that it survives and keeps evolving through time. It belongs to the Chinantecan branch of Oto-Manguean which comprises languages that display some of the most complex morphological systems known to us. The fact that Chinantecan languages are gaining attention of morphologists comes as good news for the discipline, and probably in just the right time, as it is important for linguists to join efforts to improve a theory of morphology by expanding it beyond the typological limits of the inflection of better-known European languages.

\section{References}

Ackerman, F., J. P. Blevins \& R. Malouf. 2009. Parts and wholes: Implicative patterns in inflectional paradigms, in James P. Blevins and Juliette Blevins (eds.), Analogy in Grammar: Form and Acquisition, 54-82. Oxford: Oxford University Press.

Anderson, Judy Lynn. 1989. Comaltepec Chinantec Syntax [Studies in Chinantec Languages 3]. The Summer Institute of Linguistics and the University of Texas at Arlington.

Aronoff, Mark. 1994. Morphology by itself: Stems and inflectional classes [Linguistic Inquiry Monograph 22]. Cambridge, MA: MIT Press.

Baerman, Matthew. 2012. Paradigmatic chaos in Nuer. Language 88-3: 467-94.

2013a. Inflection class interactions, in Nabil Hathout, Fabio Montermini and Jesse

Tseng (eds.), Morphology in Toulouse. Selected Proceedings of Décembrettes 7.

(LINCOM Studies in Theoretical Linguistics 51), Munich: Lincom.

— 2013b. Inflectional Classes in the languages of the Americas: an overview. Paper read at the 87th Annual Meeting of the Society for the Study of the Indigenous Languages of the Americas (SSILA), Boston, 3-6 January 2013.

— 2014a. Inflectional interactions in Oto-Manguean, in Jean-Léo Léonard and Alain Kihm (eds.), Issues in Meso-American morphology, 15-25. Paris: Michel Houdiard.

- 2014b. Covert systematicity in a distributionally complex system. Journal of Linguistics 50-1: 1-47.

Baerman, Matthew and Enrique L. Palancar. Forthcoming. The organization of Chinantec tone paradigms. Cahiers de Grammaire.

Baerman Matthew, Dunstan Brown and Greville G. Corbett. 2010. Morphological

Complexity: a typological perspective. Position paper. MS

Bonami, Olivier (ed.) 2012. Stems. Special issue of Word Structure. 
Brown, Dunstan and Andrew Hippisley. 2012. Network Morphology: A defaults-based theory of word structure. Cambridge: Cambridge University Press.

Brown, Dunstan and Roger Evans. 2013. Discovering Classes in Tlatepuzco Chinantecan. Paper presented at workshop 'Theoretical and Computational Morphology (TACMO): New Trends and Synergies', 19th International Congress of Linguists, Geneva, July 21.

Corbett, Greville G. 2006. Agreement. Cambridge: Cambridge University Press.

2007. Canonical typology, suppletion and possible words. Language, 83:8-42 2009. Canonical inflectional classes. In: Fabio Montermini, Gilles Boyé and Jesse Tseng (eds.) Selected Proceedings of the 6th Décembrettes: Morphology in Bordeaux, 1-11. Somerville, MA: Cascadilla Proceedings Project.

— 2010 Canonical derivational morphology. Word Structure 3.141-155. 1991. Gender. Cambridge: Cambridge University Press.

Corbett, Greville and Matthew Baerman. 2006. Prolegomena to a typology of morphological features. Morphology 16-2: 231-246.

Corbett, Greville and Norman Fraser. 1993. Network Morphology: A DATR account of Russian nominal inflection, Journal of Linguistics 29, 113-142.

Evans, Nicholas. 2003. Typologies of agreement: Some problems from Kayardild. Transactions of the Philological Society 101(2). 203-234.

Finkel, Raphael and Gregory T. Stump. 2007. Principal Parts and Morphological Typology. Morphology 17-1: 39-75.

- 2009. Principal parts and degrees of paradigmatic transparency, in James P. Blevins and Juliette Blevins (eds.), Analogy in Grammar: Form and Acquisition, 13-53. Oxford: Oxford University Press.

Foris, David Paul. 2000. A grammar of Sochiapam Chinantec [Studies in Chinantec Languages 6]. Dallas, TX: SIL International and the University of Texas at Arlington.

Fraser, Norman and Greville Corbett. 1994. Gender, Animacy, and Declensional Class Assignment: A Unified account for Russian, n G. Booij and J. van Marle (eds.), Yearbook of Morphology 1994, 123-150. Dordrecht: Kluwer.

Givón, Talmy. 1971. Historical syntax and synchronic morphology: An archeologist's fieldtrip. Proceedings of the Chicago Linguistic Society 7: 394-415.

Merrifield, William R. 1968. Palantla Chinantec grammar [Papeles de la Chinantla 5, Serie Científica 9]. Mexico City: Museo Nacional de Antropología.

Mugele, R. L. 1982. Tone and Ballistic Syllables in Lalana Chinantec. Unpublished Ph.D. dissertation at the University of Texas at Austin.

Müller, G. 2007. Notes on paradigm economy. Morphology 17: 1-38.

Müller, Gereon. 2004. On Decomposing Inflection Class Features: Syncretism in Russian Noun Inflection, in Gereon Müller, Lutz Gunkel, and Gisela Zifonun (eds.), Explorations in Nominal Inflection, 189-227. Berlin: Mouton de Gruyter.

Palancar, Enrique L. 2014. Revisiting the complexity of the Chinantecan verb conjugation classes, in Jean-Léo Léonard and Alain Kihm (eds.), Patterns in Meso-American Morphology, 77-102. Paris: Michel Houdiard.

Polinsky, Maria. 2003. Non-canonical agreement is canonical. Transactions of the Philological Society 101(2). 279-312. 
Rensch, Calvin. 1978. Ballistic and controlled syllables in Otomanguean Languages, in Alan Bell and Joan B. Hooper (eds.), Syllables and Segments, 85-92. Amsterdam: North Holland Publishing Company.

Rupp, James and Nadine Rupp. 1996. Diccionario chinanteco de San Juan Lealao, Oaxaca, [Vocabularios y Diccionarios Indígenas "Mariano Silva y Aceves" 35] Mexico DF: Instituto Lingüístico de Verano.

Rupp, James E. 1989. Lealao Chinantec Syntax [Studies in Chinantec Languages 2]. Dallas, TX: SIL International and the University of Texas at Arlington.

— 1990. The Lealao Chinantec syllable, in William R. Merrifield and Calvin R. Rensch (eds.), Syllable, Tones and Verb Paradigms [Studies in Chinantec Languages 4], 63-74. Dallas, TX: SIL International and the University of Texas at Arlington.

Silverman, Daniel. 1994. A Case Study in Acoustic Transparency: [spread glottis] and Tone in Chinantec. Proceedings of NELS 24. Amherst: University of Massachusetts.

Stump, Gregory. 2006. Heteroclisis and paradigm linkage. Language 82: 279-322.

Stump, Gregory and Raphael A. Finkel. 2013. Morphological Typology: From Word to Paradigm. Cambridge: Cambridge University Press.

Wurzel, Wolfgang U. 1984. Flexionsmorphologie und Natürlichkeit. Berlin: Akademie Verlag. 


\section{Appendix}

The prosodic classes of Lealao Chinantec ( ' = ballistic stress)

\begin{tabular}{|c|c|c|c|}
\hline \multirow[b]{2}{*}{ Cl. } & \multicolumn{3}{|c|}{3} \\
\hline & INCPL & CPL & IRR \\
\hline$a$ & '1 & '1 & 42 \\
\hline$b$ & 3 & 4 & 12 \\
\hline$c$ & '3 & 14 & '3 \\
\hline$d$ & '3 & '3 & 42 \\
\hline$e$ & 4 & 1 & '1 \\
\hline$f$ & 4 & 3 & 3 \\
\hline$g$ & 4 & '3 & '4 \\
\hline$h$ & 4 & 32 & 4 \\
\hline$i$ & 4 & 142 & 142 \\
\hline$j$ & 32 & 32 & 1 \\
\hline$k$ & 32 & 4 & 2 \\
\hline$l$ & 32 & 2 & 2 \\
\hline$m$ & 32 & 4 & '4 \\
\hline$n$ & '3 & '3 & '4 \\
\hline$o$ & 3 & 3 & '4 \\
\hline$p$ & 3 & '3 & 3 \\
\hline$q$ & 4 & 14 & 14 \\
\hline$r$ & 4 & 14 & 4 \\
\hline$s$ & 32 & 32 & 3 \\
\hline$t$ & 32 & 2 & 2 \\
\hline$/ 1 /$ & 1 & 1 & 1 \\
\hline ו'וl & '1 & 1 & '1 \\
\hline 121 & 2 & 2 & 2 \\
\hline /'/2/ & 12 & 2 & 2 \\
\hline $13 /$ & 3 & 3 & 3 \\
\hline / $3 /$ & 13 & 13 & 13 \\
\hline $132 /$ & 32 & 32 & 32 \\
\hline 141 & 4 & 4 & 4 \\
\hline ו'ו'/ & 14 & 14 & 14 \\
\hline $142 /$ & 42 & 42 & 42 \\
\hline
\end{tabular}

\begin{tabular}{|c|c|c|c|c|c|c|c|c|c|}
\hline \multirow[b]{2}{*}{$\mathrm{Cl}}$. & \multicolumn{3}{|c|}{$1 \mathrm{SG}$} & \multicolumn{3}{|c|}{2} & \multicolumn{3}{|c|}{ 1PL } \\
\hline & INCPL & CPL & IRR & INCPL & CPL & IRR & INCP & CPL & IRR \\
\hline 1 & '1 & '1 & '1 & '1 & '1 & '1 & '1 & '1 & '1 \\
\hline 2 & 1 & 1 & 1 & 1 & 1 & 1 & 1 & 1 & 1 \\
\hline 3 & 42 & 42 & 42 & 42 & 42 & 42 & 42 & 42 & 42 \\
\hline 4 & 32 & 12 & 1 & 32 & 2 & 1 & 32 & 2 & 1 \\
\hline 5 & 42 & 42 & 42 & 42 & 42 & 42 & 32 & 42 & 42 \\
\hline 6 & 42 & 42 & 42 & 4 & 4 & 4 & 42 & 42 & 42 \\
\hline 7 & 4 & 14 & 42 & 3 & '1 & 3 & 42 & 2 & 2 \\
\hline 8 & 42 & 42 & 42 & '1 & '1 & '1 & 2 & 2 & 2 \\
\hline 9 & 32 & 12 & 1 & '3 & 42 & 13 & 32 & 42 & 42 \\
\hline 10 & 4 & 14 & 14 & 32 & 2 & 1 & 32 & 1 & 1 \\
\hline 11 & '3 & 14 & '3 & 13 & 14 & 13 & 3 & 14 & 13 \\
\hline 12 & 42 & 42 & 42 & 3 & 3 & 3 & 32 & 32 & 32 \\
\hline 13 & 4 & 4 & 4 & '4 & 14 & 4 & 42 & 42 & 42 \\
\hline 14 & 14 & 14 & '4 & 14 & 42 & 14 & 32 & 42 & 42 \\
\hline 15 & 14 & 14 & 14 & 14 & 14 & 4 & 32 & 42 & 42 \\
\hline 16 & 4 & 14 & 42 & 3 & 3 & 3 & 32 & 2 & 2 \\
\hline 17 & 32 & 12 & 1 & '3 & 12 & 13 & 32 & 42 & 42 \\
\hline 18 & 42 & 42 & 42 & 4 & 4 & 4 & 32 & 32 & 32 \\
\hline 19 & 4 & 14 & 4 & 32 & '1 & 1 & 32 & 2 & 2 \\
\hline 20 & 4 & 14 & 42 & 3 & 3 & 3 & 32 & 2 & 2 \\
\hline 21 & 14 & 14 & 4 & 32 & '1 & 1 & 32 & 2 & 2 \\
\hline 22 & 4 & 4 & 4 & 3 & 3 & 3 & 32 & 32 & 32 \\
\hline 23 & 14 & 14 & 4 & 32 & '1 & 1 & 4 & 2 & 2 \\
\hline 24 & 32 & 2 & 1 & 14 & 14 & 14 & 32 & 42 & 42 \\
\hline 25 & 32 & 2 & 1 & 4 & 14 & 14 & 42 & 42 & 42 \\
\hline 26 & 32 & 32 & 1 & 32 & 32 & 1 & 32 & 32 & 1 \\
\hline 27 & 4 & 4 & 4 & '1 & '1 & '1 & 2 & 2 & 2 \\
\hline 28 & 42 & 42 & 42 & 4 & 14 & 14 & 42 & 4 & 14 \\
\hline 29 & 4 & 4 & 4 & 32 & 12 & 1 & 32 & 42 & 42 \\
\hline 30 & 42 & 42 & 1 & 42 & 42 & 42 & 42 & 42 & 42 \\
\hline 31 & 32 & 12 & 1 & 3 & 3 & 3 & 32 & 2 & 2 \\
\hline 32 & 32 & 2 & 1 & '3 & 2 & '3 & 32 & 1 & 1 \\
\hline 33 & 4 & 4 & 4 & 3 & 3 & 3 & 42 & 42 & 42 \\
\hline 34 & 4 & 14 & 4 & 4 & 14 & 4 & 42 & 4 & 42 \\
\hline 35 & 42 & 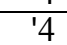 & 42 & 4 & 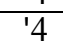 & 4 & 14 & 14 & 42 \\
\hline 36 & 4 & 14 & 42 & '3 & 3 & 3 & 42 & 42 & 42 \\
\hline 37 & 4 & 4 & 42 & '1 & '1 & '1 & 42 & 2 & 2 \\
\hline 38 & 14 & 14 & 4 & '2 & '2 & 12 & 4 & 14 & 14 \\
\hline 39 & 14 & 14 & 4 & 32 & 2 & 12 & 32 & 32 & 32 \\
\hline 40 & 14 & 14 & '4 & 32 & 2 & 1 & 42 & 1 & 1 \\
\hline 41 & 42 & 42 & 4 & 42 & 42 & 42 & 42 & 42 & 42 \\
\hline 42 & 42 & 12 & 1 & '1 & 13 & 13 & 2 & 2 & 2 \\
\hline 43 & 32 & 32 & 42 & 4 & 32 & 4 & 42 & 32 & 42 \\
\hline 44 & 4 & 14 & 42 & '3 & 13 & 13 & 2 & 2 & 2 \\
\hline 45 & 4 & 14 & 42 & '3 & '3 & 13 & 32 & 2 & 2 \\
\hline 46 & 4 & 12 & 1 & 13 & '1 & 13 & 3 & 2 & 2 \\
\hline 47 & 4 & 14 & 42 & '1 & '1 & '1 & 42 & 2 & 2 \\
\hline 48 & 4 & 14 & 42 & '1 & '1 & 1 & 2 & 2 & 2 \\
\hline 49 & 32 & 12 & 1 & '3 & '1 & 13 & 3 & 2 & 2 \\
\hline 50 & 32 & 2 & 1 & 32 & '1 & 1 & 14 & 2 & 2 \\
\hline 51 & 42 & 2 & 1 & 42 & '2 & 1 & 42 & 42 & 42 \\
\hline 52 & 42 & 12 & 1 & 42 & 4 & 4 & 42 & 42 & 42 \\
\hline 53 & 4 & 4 & 4 & 1 & '1 & '1 & '1 & '1 & '1 \\
\hline 54 & 14 & '4 & '4 & 32 & '1 & 1 & 32 & 2 & 2 \\
\hline 55 & '4 & '4 & '4 & 32 & '2 & 1 & 32 & 2 & 2 \\
\hline 56 & '4 & '4 & '4 & '1 & '1 & '1 & 2 & 2 & 2 \\
\hline 57 & 14 & 14 & 14 & 2 & 2 & 2 & 32 & 32 & 32 \\
\hline 58 & 42 & '4 & 42 & '1 & 3 & 3 & 2 & 2 & 2 \\
\hline
\end{tabular}




\begin{tabular}{|c|c|c|c|c|c|c|c|c|c|}
\hline 59 & 42 & 42 & 42 & 3 & 3 & 3 & 3 & 3 & 3 \\
\hline 60 & 42 & 42 & 42 & '1 & '1 & '1 & 2 & 2 & 2 \\
\hline 61 & 4 & '4 & 42 & 3 & '2 & 3 & 2 & 2 & 2 \\
\hline 62 & 32 & 12 & 1 & 4 & 4 & 4 & 32 & 42 & 42 \\
\hline 63 & 42 & 42 & 42 & 32 & '1 & 1 & 32 & 42 & 42 \\
\hline 64 & 32 & 12 & 1 & 3 & '1 & '3 & 32 & 1 & 1 \\
\hline 65 & 14 & 4 & '4 & 3 & 3 & 3 & 32 & 32 & 32 \\
\hline 66 & 42 & 4 & 4 & 4 & 4 & 4 & 32 & 4 & 4 \\
\hline 67 & 4 & 4 & 4 & 1 & 1 & 1 & 1 & 1 & 1 \\
\hline 68 & 14 & 12 & 1 & 32 & 4 & 4 & 32 & 42 & 42 \\
\hline 69 & 42 & 3 & 4 & 4 & '3 & '4 & 42 & '3 & '4 \\
\hline$l$ & 32 & 2 & 2 & 32 & 2 & 2 & 32 & 2 & 2 \\
\hline$q$ & 4 & 4 & 4 & 4 & 4 & '4 & 4 & 14 & 14 \\
\hline /1/ & 1 & 1 & 1 & 1 & 1 & 1 & 1 & 1 & 1 \\
\hline /'II & '1 & '1 & '1 & '1 & '1 & '1 & '1 & '1 & '1 \\
\hline$/ 2 /$ & 2 & 2 & 2 & 2 & 2 & 2 & 2 & 2 & 2 \\
\hline /'2/ & 2 & 2 & 2 & 2 & 2 & 2 & 2 & 2 & 2 \\
\hline$|3|$ & 3 & 3 & 3 & 3 & 3 & 3 & 3 & 3 & 3 \\
\hline /'3/ & 3 & 3 & 3 & 3 & 3 & 3 & 3 & '3 & 3 \\
\hline $132 /$ & 32 & 32 & 32 & 32 & 32 & 32 & 32 & 32 & 32 \\
\hline 141 & 4 & 4 & 4 & 4 & 4 & 4 & 4 & 4 & 4 \\
\hline /'4/ & 14 & '4 & '4 & 14 & '4 & 14 & '4 & 14 & '4 \\
\hline 1421 & 42 & 42 & 42 & 42 & 42 & 42 & 42 & 42 & 42 \\
\hline
\end{tabular}

